\title{
Eukaryotic Protein Kinases (ePKs) of the Helminth Parasite Schistosoma mansoni
}

\author{
Luiza F Andrade ${ }^{1 \dagger}$, Laila A Nahum ${ }^{1,2+}$, Lívia GA Avelar ${ }^{1,3}$, Larissa L Silva ${ }^{1,2,3}$, Adhemar Zerlotini ${ }^{2}$, Jerônimo C Ruiz \\ and Guilherme Oliveira ${ }^{1,2^{*}}$
}

\begin{abstract}
Background: Schistosomiasis remains an important parasitic disease and a major economic problem in many countries. The Schistosoma mansoni genome and predicted proteome sequences were recently published providing the opportunity to identify new drug candidates. Eukaryotic protein kinases (ePKs) play a central role in mediating signal transduction through complex networks and are considered druggable targets from the medical and chemical viewpoints. Our work aimed at analyzing the S. mansoni predicted proteome in order to identify and classify all ePKs of this parasite through combined computational approaches. Functional annotation was performed mainly to yield insights into the parasite signaling processes relevant to its complex lifestyle and to select some ePKs as potential drug targets.

Results: We have identified 252 ePKs, which corresponds to 1.9\% of the S. mansoni predicted proteome, through sequence similarity searches using HMMs (Hidden Markov Models). Amino acid sequences corresponding to the conserved catalytic domain of ePKs were aligned by MAFFT and further used in distance-based phylogenetic analysis as implemented in PHYLIP. Our analysis also included the ePK homologs from six other eukaryotes. The results show that S. mansoni has proteins in all ePK groups. Most of them are clearly clustered with known ePKs in other eukaryotes according to the phylogenetic analysis. None of the ePKs are exclusively found in S. mansoni or belong to an expanded family in this parasite. Only $16 \mathrm{~S}$. mansoni ePKs were experimentally studied, 12 proteins are predicted to be catalytically inactive and approximately $2 \%$ of the parasite ePKs remain unclassified. Some proteins were mentioned as good target for drug development since they have a predicted essential function for the parasite.

Conclusions: Our approach has improved the functional annotation of $40 \%$ of S. mansoni ePKs through combined similarity and phylogenetic-based approaches. As we continue this work, we will highlight the biochemical and physiological adaptations of S. mansoni in response to diverse environments during the parasite development, vector interaction, and host infection.
\end{abstract}

\section{Background}

Human schistosomiasis caused by blood fluke parasites of Schistosoma genus, remains an important parasitic disease and a major health economic problem in many tropical and subtropical countries. Schistosomes have a complex life cycle that includes six different stages (cercariae, schistosomula, adult worms - male and female, egg, miracidia and sporocyst) in different environments: water, definitive

\footnotetext{
* Correspondence: oliveira@cpqrr.fiocruz.br

+ Contributed equally

'Genomics and Computational Biology Group, Instituto Nacional de Ciência e Tecnologia em Doenças Tropicais, Centro de Pesquisas René Rachou, Fundação Oswaldo Cruz - FIOCRUZ, Belo Horizonte, MG- 30190-002, Brazil Full list of author information is available at the end of the article
}

host (mammals) and intermediate host (snail). During parasite development, signals from the environment are sensed and stimulate physiological, morphological and, biochemical adaptations. Oils are shown to stimulate cercarial penetration; hormones and exposure to the snail haemolymph trigger specific physiological adaptations [1-3]. The free living parasite forms display light and geotropism and female development is dependent on signals from the male adult worm through mechanisms not completely understood $[4,5]$. It has been demonstrated that worm pairing induces changes in gene expression in the female vitelline gland [4] and the accumulation of glutathione and lipids in the male [5]. Furthermore, microarray analysis revealed distinct differential gene expression

\section{Biomed Central}


profiles between males and females [6-8]. Therefore, the success of the parasite infection depends on the assessment at the cellular and molecular levels of the environment and the transmission of signals to physiological regulatory networks that will collectively stimulate adaptations.

The maintenance of homeostasis and complex cellular adaptations in Schistosoma mansoni require specific extracellular signals that must be integrated to generate an appropriate response from the sensory receptor via intracellular proteins [3]. Signal transduction involves non-linearly integrated networks that interact mostly by switching activity status via phosphorylation (protein kinases) and dephosphorylation (protein phosphatases) of amino acid residues, or the incorporation of GTP. Other cellular non-protein messengers include cyclic AMP, $\mathrm{Ca}^{2+}$ and diacylglycerol.

Protein kinases (PKs) play a central role in mediating intracellular signals by adding a phosphate group from ATP or GTP to an amino acid residue leading to a conformational change in the target protein that will switch its activation status [9]. Most PKs have a catalytic domain, which binds and phosphorylates target proteins, and a regulatory region. Many PKs are autophosphorylated or may be phosphorylated by other PKs, an interaction regulated by the accessory protein domains [10].

PKs are classified into two superfamilies containing the eukaryotic or conventional protein kinases (ePK) that share a conserved catalytic domain, and the atypical protein kinases (aPKs) (Table 1). The catalytic domain of ePKs is composed of 250-300 amino acids and is divided into 12 subdomains with highly conserved individual amino acids and motifs [11]. aPKs are reported to have biochemical kinase activity, but lack sequence similarity to the ePK catalytic domain [12]. According to their substrate recognition sites, ePKs are divided broadly into two major classes, serine/threonine kinases (STKs) and tyrosine kinases (TKs). Dual specificity kinases (Hybrid), which phosphorylate serine, threonine, and tyrosine, are

Table 1 Protein kinase classification

\begin{tabular}{ccc}
\hline Superfamily & Class & Group \\
\hline & Serine/Threonine Kinases & AGC \\
& & CaMK \\
& & CMGC \\
& & STE \\
Eukaryotic Protein Kinases (ePKs) & CK1 \\
\cline { 2 - 3 } & & Tyrosine Kinases \\
\cline { 2 - 3 } & & TK \\
& HGC \\
\hline
\end{tabular}

Protein kinases are broadly classified into two major superfamilies (ePKs and aPKs). The ePKs groups, families, and subfamilies adopted in the present work followed the proposed hierarchy described elsewhere $[15,16,27]$. also found. ePKs have been further classified into eight groups based on sequence similarity of their catalytic domains, the presence of accessory domains, and their modes of regulation [9,12-14]. According to KinBase [15], a database that holds information of PKs encoded in the human genome and their homologs in other eukaryotes, the eight ePK groups are: AGC (cAMP-dependent protein kinase/protein kinase $\mathrm{G} /$ protein kinase $\mathrm{C}$ extended), CAMK (Calcium/Calmodulin regulated kinases), CK1 (Cell Kinase I), CMGC (Cyclin-dependent Kinases and other close relatives), RGC (Receptor Guanylate Cyclases), STE (MAP Kinase cascade kinases), TK (Protein Tyrosine Kinase) and TKL (Tyrosine Kinase Like). A ninth group, called "Other", consists of a mixed collection of kinases that cannot be classified easily into the previous families [14] (Table 1).

PKs are considered druggable targets from the medical and chemical viewpoints as a growing number of PKs inhibitors have been developed and approved for treatment of different human disease [16]. An example of a successful PK inhibitor is Gleevac ${ }^{\circledR}$, that induces a conformational change in PTK and mimics substrate binding and therefore prevents activation by upstream kinases [17]. Beyond this, PKs have gained interest as targets treatment strategies to fight many parasites, including $S$. mansoni [18-21].

The current schistosomiasis treatment frequently does not cure $100 \%$ of those treated in high-risk communities and the emergence of Schistosoma resistant strains is a real possibility [22-25]. Thus, the identification of potential drug targets should be further emphasized. The recent sequencing of $S$. mansoni genome and large-scale transcriptome projects have yielded crucial information to the identification of new candidate drugs [26-29]. Understanding protein structure and function in many model organisms can help elucidate the function of their parasite homologs and further enable the application of such information in drug design and development. The study of the kinase complement (kinome) is therefore of major importance for the understanding of the physiology of the organism and also provides insights into how to disrupt the fine adaptative mechanisms. The present work aimed at analyzing the $S$. mansoni predicted proteome data in order to identify all ePKs encoded in the genome of this parasite. For this purpose, we combined computational approaches such as sequence similarity searches using Hidden Markov Models (HMMs) and distance-based phylogenetic analyses. The functional annotation was performed mainly to yield insights into the signaling process related to the complex lifestyle of S. mansoni.

\section{Results and discussion}

\section{The Schistosoma mansoni ePKinome}

The ePK complement of $S$. mansoni, defined as the ePKinome, was identified by searching the parasite 
predict proteome with a HMM profile of the ePK catalytic domain of five selected organisms. This analysis revealed 252 ePKs in the $S$. mansoni predicted proteome, representing $1.9 \%$ of the total proteins encoded in the parasite genome. Although the total number of protein kinases found across the analyzed species varies greatly (from 82 to 503), the percentage values in respect to the genomes of protozoan and helminth parasites as well as other eukaryotes from KinBase range only between 1.5 to $2 \%$ (Figure 1 ).

Amino acid sequences corresponding to the conserved catalytic domain of ePKs were aligned by MAFFT [30] and further used in phylogenetic analysis based on a distance method as implemented in PHYLIP [31]. The dataset for each ePK group also included the ePK homologs from six other eukaryotes: Homo sapiens, Mus musculus, Drosophila melanogaster, Caenorhabditis elegans, Saccharomyces cerevisiae, and Brugia malayi. This approach allowed us to classify the S. mansoni ePKinome at the group, family, and/or subfamily levels based on the hierarchy proposed elsewhere $[12,13,32,32]$, and sometimes provided insights into kinase function and evolution. Detailed information is available in the Additional file 1 that contains, among other things, all S. mansoni ePKs with the corresponding identifier from the genome project linked to SchistoDB database [29]. SchistoDB http://www. schistodb.net allows the community to access to all sequences, annotations and other data types integrated

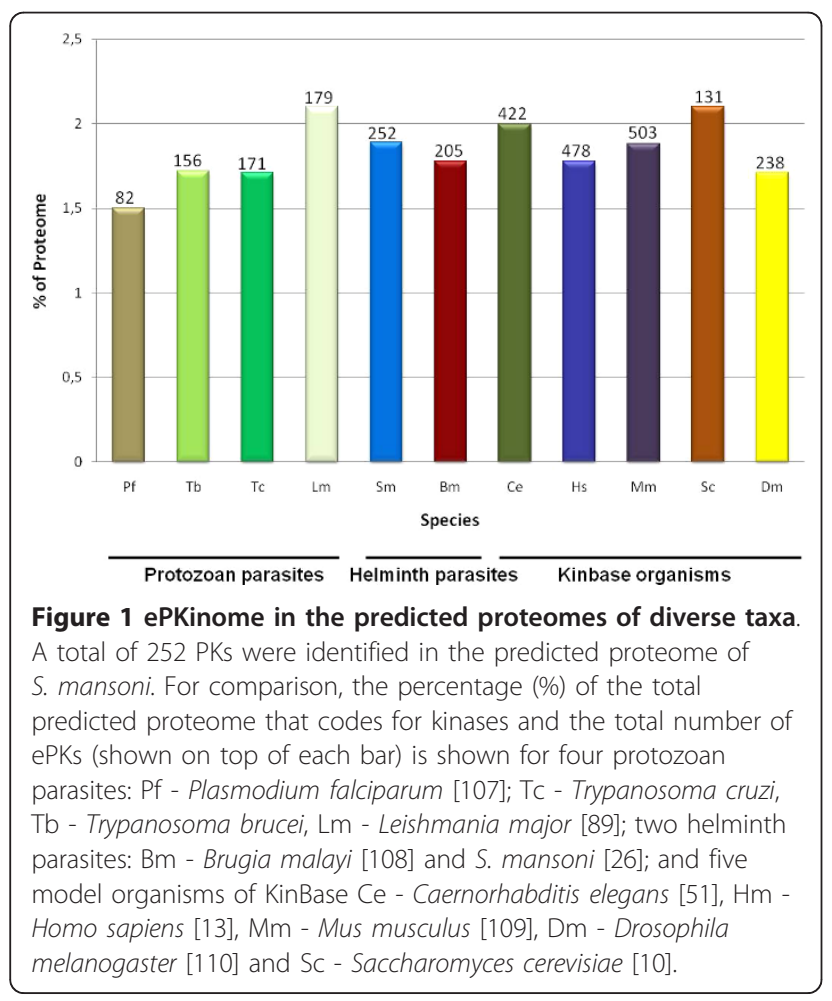

into the genomic information. It also provides several tools to analyze retrieve and display the data. In the SchistoDB it is possible to encounter, for each ePK, the development expression stages by EST evidence, information about orthologs, Gene Onthology (GO) function, metabolic pathways, structural information, PDB structures, and links to external databases such as the TDR database [33]. The TDR database contains additional information for S. mansoni genes like antigenicity, essentiality, phenotypes and associated compounds (druggability).

As shown in Figure 2, S. mansoni proteins have representatives in the main ePK groups. ePKs that do not fall into these groups are categorized as "Other" in which multiple families have been defined. The S. mansoni largest ePK group is CMGC, a feature unique to this parasite, and the smallest group is RGC, a common feature shared with many of the analyzed organisms (Figure 2).

Of the $252 \mathrm{ePKs}$ identified in S. mansoni proteome, only 16 were experimentally studied as highlighted in the supplementary material (Additional file 1) and the others $236 \mathrm{ePKs}$ were previously annotated only by automatic methods based on sequence similarity searches [26,29].

S. mansoni ePKs were examined for the presence of the 12 smaller subdomains present in the catalytic domain and also for the presence of a lysine in subdomain II and aspartic acids residues in subdomain VIb and VII, which are known to play essential roles in the kinase function $[9,12,34]$. According to our analysis, 12 proteins are predicted to be catalytically inactive ePKs, as they lack one or more of the three essential amino acid residues in the catalytic domain (Additional file 1), including all members of $S$. mansoni RGC group (see below).

Approximately $2 \%$ of the $S$. mansoni ePK remain unclassified once they do not have similarity to any

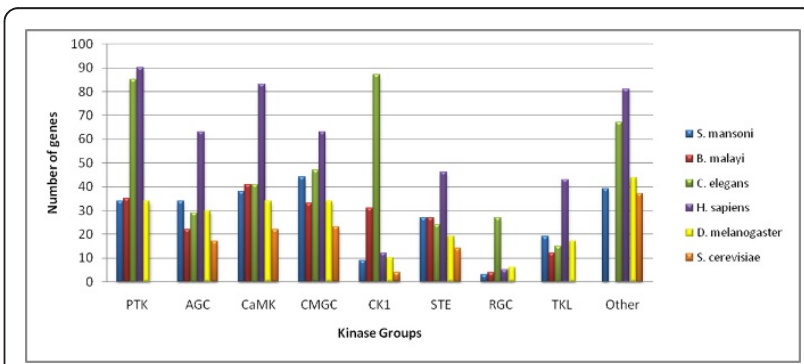

Figure 2 Distribution of ePKs groups in S. mansoni and model organisms. S. mansoni proteins were classified according to KinBase [15] by combining sequence searches (HMMs) and phylogenetic analysis. For comparison, occurrence of the ePKs in B. malayi, C. elegans, H. sapiens, D. melanogaster, S. cerevisiae, and is shown. The ePK groups include: PTK (Protein Tyrosine Kinase), AGC (cAMPdependent protein kinase/protein kinase G/protein kinase $C$ extended), CaMK (Calcium/Calmodulin regulated kinases), CMGC (Cyclin-dependent Kinases and other close relatives), CK1 (Cell Kinase I), STE (MAP Kinase cascade kinases), RGC (Receptor Guanylate Cyclases), TKL (Tyrosine Kinase Like), and Other. 
known PK family. All these proteins have a truncated catalytic domain probably because of an incorrect protein prediction. The unclassified ePKs from $C$. elegans, $D$. melanogaster, $H$. sapiens and S. cerevisiae range from $19 \%$ to about $38 \%$ their kinomes.

\section{Serine/Threonine kinases \\ AGC group}

Around 13 families have been classified as part of the AGC group in eukaryotic organisms [11]. In S. mansoni, most AGC proteins belong to PKA (Protein Kinase A) (5 proteins), DMPK (Myotonic Dystrophy Protein Kinase) (4 proteins and 1 product of alternative splicing), PKC (Protein Kinase C) (4 proteins) and PKG (4 proteins) families. Other $S$. mansoni proteins have only one representative in the remaining AGC families (Additional file 1). According to our phylogenetic analysis, S. mansoni has no homolog of the YANK (Yet Another Novel Kinase) family (Additional file 2).

The most significant difference between PKA and PKG family members is that in PKA, the regulatory and catalytic activities are performed by separate gene products known as PKA-R and PKA-C, respectively, whereas in PKG the cNMP-binding (cyclic nucleotide-binding domain) and catalytic domains are usually present in the same polypeptide [35]. The inactive conformation of PKA is a heterotetramer of two PKA-R and two PKA-C subunits, while PKG exists as a homodimer [35]. S. mansoni processes five homologs of the PKA-C subunit (Additional file 1), and six predicted of PKC-R subunit (Smp_131050, Smp_147320, Smp_079010, Smp_030400, Smp_019280, Smp_022100) allowing for a variety of different holoenzymes to be formed in this parasite. Some studies demonstrated that PKG proteins of Toxoplasma [36] and Eimeria [37] and PKG and PKA proteins of Plasmodium [38,39] are essential as the inhibitors causes an anti-parasite effect in these organisms. Recently it was shown that inhibition of the SmPKA-C subunit (Smp_152330), expressed in adult worms of $S$. mansoni, resulted in the death of the parasites [40]. This result and the range of holoenzymes that can be formed, indicate that genes in this family are critical for the development of S. mansoni and may represent good targets for drug development.

PKC belongs to a large protein family that is classified into four important subfamilies: PKC Alpha subfamily, that contain the conventional PKCs $(\gamma, \beta \mathrm{I}, \beta \mathrm{II}$, and $\alpha)$ and are sensitive to diacylglycerol (DAG) and $\mathrm{Ca}^{2+}$; PKC Eta and Delta subfamilies containing the novel PKCs $(\varepsilon$, $\delta, \eta$, and $\theta$ ) which are regulated by DAG alone; and PKC Iota subfamily, that contain the atypical PKCs $(\zeta$ and $\iota)$, and are insensitive to both compounds $[41,42]$. PKC is considered to be a mechanistic regulator of development in vertebrates, playing a key role in cell growth and differentiation [43-45]. S. mansoni has representatives in the three main PKC subfamilies mentioned above (Iota, Eta and Alpha) but lacks homologs in the Delta subfamily, present in C. elegans, D. melanogaster, M. musculus, and $H$. sapiens. The two PKC Alpha proteins found in S. mansoni (Smp_128480 and Smp_176360), belong to the PKC $\beta$ I isoform and were recently characterized [46-48]. Both are associated with the neural mass, excretory vesicle, ridge cyton, tegument and germinal cells in schistosomula and miracidium, suggesting a possible role in larval transformation [46-48].

One protein in AGC group, Smp_157370, remains unclassified. In the phylogenetic tree, this protein appears more closely related to the GRK (G-protein coupled Receptor Kinase) family (Additional file 2), despite the good conservation of the catalytic domain, this protein lacks the accessory domain that is characteristic of the GRK proteins (Additiona file 2). Furthermore, Smp_ 157370 does not form a clade with the GRK family members according to our phylogenetic tree, which corroborates its divergence in relation to GRK homologs in other eukaryotes (Additional file 2).

Interestingly, according to SchistoDB [29] EST evidences, the two most highly transcribed ePKs (Smp_151140 and Smp_158560.1) in S. mansoni, belong to the DMPK family of the AGC group, mainly in cercariae, schistosomula, eggs and adult worms. This finding is interesting as these are the four life cycle stages of the parasite which are in contact with the definitive host. In C. elegans proteins of DMPK family are expressed in hypodermal cells and are involved in embryonic elongation [49].

\section{CaMK group}

The divalent cation calcium $\left(\mathrm{Ca}^{2+}\right)$ is one of the ions most widely used as a second messenger in cellular signaling. A significant portion of calcium-mediated signaling is controlled by calmodulin-binding kinases. Some members of the CaMK group are dependent on the binding of $\mathrm{Ca}^{2+} / \mathrm{CaM}$ [50]. In the S. mansoni ePKinome, 32 proteins were classified as CaMK with the vast majority (18 proteins) belonging to the CaMKL (Calcium/Calmodulin Regulated Kinase) - like family. A similar number was found in other organisms analyzed here (Additional file 3). S. mansoni also contain members of DAPK (death associated protein kinase), MAPKAPK (MAPK associated protein kinase), MLCK (myosin light chain kinase), and PHK (phosphorylase kinase) families in the CaMK group (Additional file 4).

MLCK is a $\mathrm{Ca}^{2+} /$ calmodulin-dependent protein kinase whose only known substrate is myosin II regulatory light chain [51]. The primary function of MLCK is to stimulate muscle contraction through the phosphorylation of the myosin II regulatory light chain (RLC), a eukaryotic motor protein that interacts with filamentous actin. Although MLCK has only one known substrate (RLC), 
this protein is linked to a variety of cellular processes due to the diverse biological function of myosin II [50]. Two distinct smooth muscle MLCK genes were identified in S. mansoni (Smp_121780, Smp_126240), although no homologs were identified for the non-smooth muscle vertebrate MLCK through our phylogenetic analysis. This likely reflects the absence of a striated muscle in this parasite.

DCAMKL (Doublecortin and CaMK-like) is a protein that regulates the microtubule cytoskeleton and in the chick is specifically expressed in the developing brain $[52,53]$. CASK is a protein that participates in cell adhesion [54]. According to our phylogenetic analysis, a single homolog of the DCAMKL (Smp_053560) and CASK (Smp_131690) families were found in S. mansoni (Additional file 4).

While the CaMK2 (CaMK family 2) family is encoded by four genes in humans, only a single CaMK2 gene, with two predicted alternative spliced transcripts, was identified in the $S$. mansoni genome (Additional file 1). S. mansoni CaMK2 was recently identified as putative target for drug development after comparative chemogenomics approach using the $S$. mansoni proteome and the proteome of two model organisms, C. elegans and D. melanogaster. [55]. The function of this protein in $S$. mansoni is still unknown. In sea urchin, CaMK2 is required for nuclear envelope breakdown following fertilization [56].

\section{CMGC group}

CMGC kinases are relatively abundant in $S$. mansoni, a feature that can be explained by the requirement to control cell proliferation and to ensure correct replication and segregation of organelles, which together are essential mechanisms for parasites with a complex life cycle. In the CMGC group, all of the main families are conserved between $S$. cerevisiae, C. elegans, $M$. musculus, $H$. sapiens, and S. mansoni, including CDK (Cyclin Dependent Kinase), MAPK (Mitogen Activated Protein Kinase), GSK (Gycogen Synthase 3 Kinase), CLK (CDC-Like Kinase), SRPK (SR Protein Kinase), CK2 (Cell Kinase 2), and DYRK (Dual-specificity Tyrosine Regulated Kinase) (Additional file 5) and RCK.

S. mansoni has $14 \mathrm{CDKs}$, the same number was found in C. elegans (compared with only seven in S. cerevisiae), including homologs of all subfamilies (CDK7, CDK4, CDK8, CRK7, CDK9, PITSLRE, CDK10, PCTAIRE, PFTAIRE, VDK5 and CDC2) (Additional file 5). On the other hand, only one RCK family protein (Smp_132890) was identified in the parasite. The RCK proteins are similar to mammalian MAK (male germ cell-associated kinase), which have been implicated in spermatogenic meiosis and in signal transduction pathways for sight and smell [51].

GSK family is represented by 3 proteins in S. mansoni. One of those (Smp_008260.1) was selected as putative target for drug development after comparative chemogenomics approach [55]. GSK proteins are involved in development and cell proliferation, are overexpressed in colon carcinomas and positively regulates the Wnt signaling pathway during embryonic development and oocyte-to-embryo transition in C. elegans [57].

The MAPK signaling pathways are some of the best characterized signaling systems. S. mansoni contains nine MAPKs, compared to seven in D. melanogaster and 14 in C. elegans. As shown in Figure 3, mammals have, at least five MAPK cascades described; these include the extracellular signal-regulated kinase (ERK) cascade, which regulates cell growth and differentiation, the c-Jun N-terminal kinase (JNK)/stress-activated protein kinase (SAPK), and the p38 MAPK cascades, which function mainly in stress responses such as inflammation and apoptosis [58]. In D. melanogaster and C. elegans, the MAPK pathways are involved in critical cellular and developmental processes $[59,60]$. S. cerevisiae has four distinct MAPK signaling pathways that are likely mediators of responses to pheromone, nutritional starvation, and cellular or osmotic stress [51]. The MAPK signaling pathways are well conserved in $S$. mansoni (Figure 3), including representatives of the subfamilies ERK, p38, JNK, and, NLK but lacks members of ERK5 that are part of a signaling pathways found mainly in mammals (Additional file 5). Each subfamily is activated by different stimuli that generate different biological responses [61-63]. In S. mansoni only one protein was identified in JNK (Smp_172240) subfamily. JNK proteins play key roles in human cell function [62] and in the development of C. elegans worms [64]. JNK may have an important role in schistosome survival and represent a good target for experimental approaches.

\section{STE group}

In S. mansoni, the STE group includes seven STE7 (MEK or MAPKK), two STE11 (MEKK or MAPKKK), and 13 STE20 (MEKKK) kinases (Additional file 6). The large number of STE family members in S. mansoni could translate into an enormous potential for downstream signal specificity and diversity. SmSLK (Smp_150260) is a Ste20 family protein, recently characterized in $S$. mansoni, which is able to activate protein MAPK/JNK in human embryonic kidney (HEK) cells as well as in Xenopus oocytes. In addition, imunofluorescence showed that SmSLK was abundant in the tegument of adult schistosomes [65]. These findings indicate that signals sensed in the environment by many different proteins may activate the MAPK cascade that will generate an adaptive physiological response. Futhermore, molecules that activate the MAPK pathways, as some hormone and cytokine signals, are not found in the $S$. mansoni predicted proteome (Figure 3). It has been demonstrated that the parasite takes advantage of 


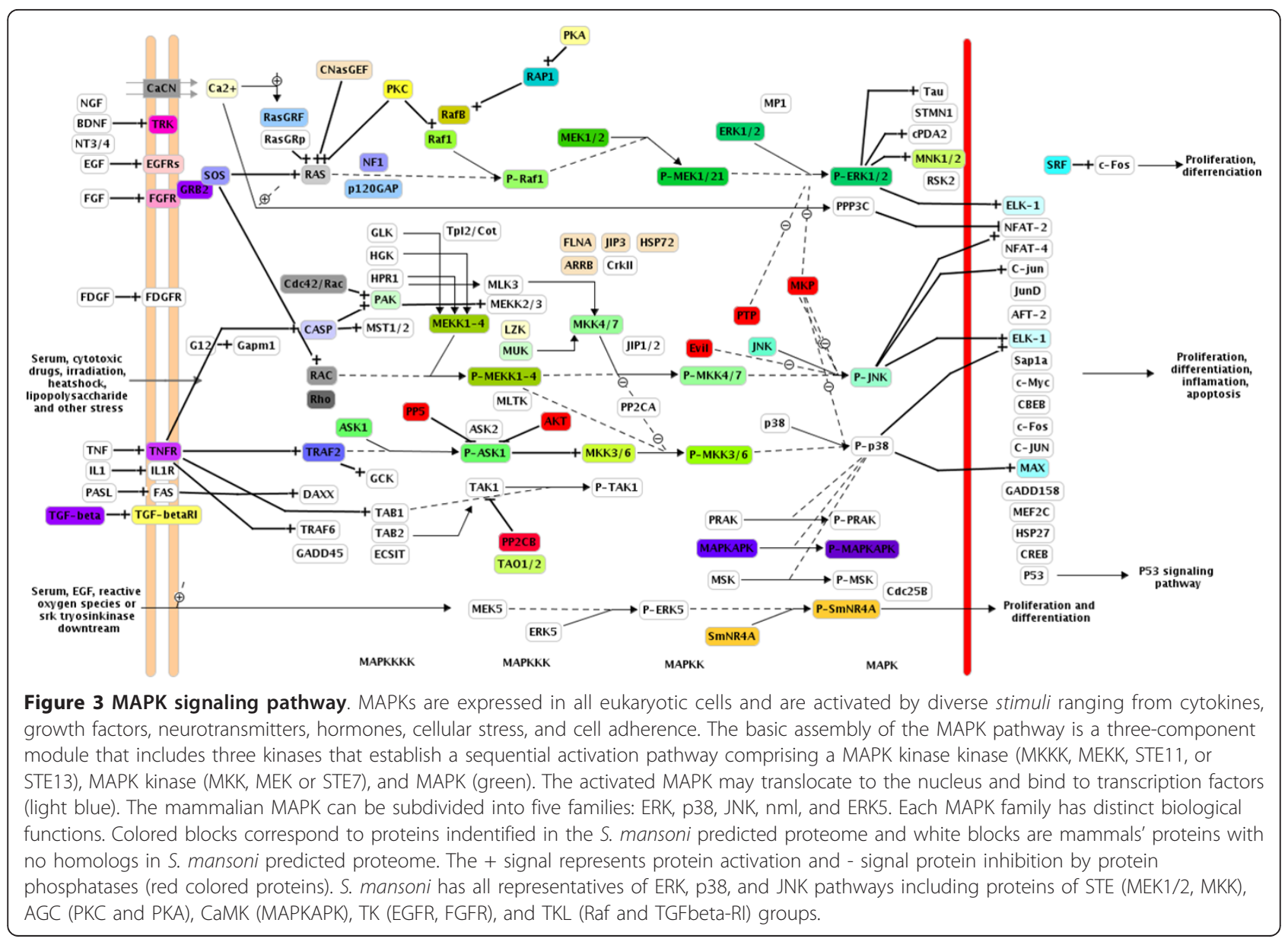

host proteins for its growth and development $[66,67]$. Other ePKs such as members of the PKA, PKC, Raf and receptor protein tyrosine kinases (RTKs) families, also participate in MAPK signaling pathway. RTKs are anchored to the membrane and have an important role in transmitting the signal from the extracellular to cytoplasm (Figure 3) [64].

In C. elegans genome studies such as classical forward genetic and RNA interference screens and systematic targeted gene knockout revealed genes that are essential to the organism [68]. Although the off-target and nonspecific effect of RNAi [69,70], in S. mansoni this is one of the best approaches to explore the functional property of the genes since the knockout experiments are not yet available for schistosomes [71]. By analyzing the phylogenetic trees of the present work, it was possible to identify the proteins of $S$. mansoni that have homologs in C. elegans and display lethality and sterile phenotypes by RNAi (Table 2). Interestingly, most essential proteins in table 2 belong to the CMGC and STE groups, suggesting the involvement of these proteins in signaling pathways that culminate in essential cellular processes.

\section{CK1 Group}

The two smallest groups found in the $S$. mansoni ePKinome were CK1 and RGC (Figure 2). In contrast, in C. elegans CK1 is the largest group and RGC is dramatically expanded. However, these expansions are a unique feature of C. elegans, as compared to other eukaryotes selected for this analysis (Figure 4). The CK1 group consists of three main ePK families: CK1, VRK (Vaccinia Related Kinase), and TTBK (Tau Tubulin Kinase) that formed three individual clusters in the phylogenic tree (Figure 4). S. mansoni has representatives in each of these families also found in C. elegans, D. melanogaster, M. musculus, $H$. sapiens, S. cerevisiae and B. malayi kinomes. The nematodes, C. elegans and B. malayi, still have two other families that seem to be specific to this taxonomic group, TTBKL and Worm6. The Worm8 family was identified only in Caenorhabditis so far. The diversification of the CK1 group in C. elegans may be an adaptation allowing for enhanced DNA repair in response to excessive exposure to environmental mutagens [51]. One CK1 encoding gene (spe-6) functions in spermatogenesis, and at least half of the proteins in this group are selectively expressed in C. elegans sperm as 
Table 2 Orthology relationships among ePKs of S. mansoni, B. malayi, and C. elegans and RNAi phenotype for C. elegans proteins

\begin{tabular}{|c|c|c|c|c|}
\hline Group & S. mansoni & C. elegans & $\begin{array}{l}\text { Brugi } \\
\text { malayi }\end{array}$ & C. elegans RNAi phenotype \\
\hline \multicolumn{5}{|l|}{ CaMK } \\
\hline & Smp_053560 & C44C8.6_Ce e K08F8.1 & - & Embryonic Lethal \\
\hline \multicolumn{5}{|l|}{ AGC } \\
\hline & Smp_123640 & F19C6.1_Ce & - & Embryonic lethal, maternal sterile, organism morphology variant. \\
\hline & Smp_136750 & Y47D3A.16_Ce & Bm1_44635 & Larval lethal, fertility reduced \\
\hline & Smp_158560 & K08B12.5_Ce & Bm1_02320 & Body morphology defect, slow growth \\
\hline & Smp_096310 & pkc-3_Ce_A & Bm1_03335 & Embryonic lethal, sterile, body morphology defect \\
\hline \multicolumn{5}{|l|}{ TK } \\
\hline & Smp_139480 & vab-1_Ce_T & Bm1_03410 & Embryonic lethal, body morphology defect \\
\hline \multicolumn{5}{|l|}{ STE } \\
\hline & Smp_026510, Smp_151670 & mek-2_Ce & - & $\begin{array}{c}\text { Embryonic lethal, sterile, reduced brood size, exploted through } \\
\text { vulva, slow growth }\end{array}$ \\
\hline & Smp_096640 & gck_1_Ce & - & cortical dynamics defective early embryonic, maternal sterile \\
\hline & Smp_163420 & mig_15_Ce & Bm1_32540 & Abnormal cell migration, protruding vulva, developmental delay \\
\hline & Smp_068060 & kin_18_Ce & Bm1_55590 & $\begin{array}{c}\text { Embryonic lethal, body morphology defect, slow growth, sterile, } \\
\text { larval lethal, dumpy }\end{array}$ \\
\hline & Smp_131800 & Y59A8B.23_CE & Bm1_11845 & More depolarized oocytes \\
\hline & Smp_150260 & C04A11.3_Ce & Bm1_26435 & Slow growth, larval lethal late $L 3 / L 4$ \\
\hline \multicolumn{5}{|l|}{ TKL } \\
\hline & Smp_079760 & pat4_Ce_TK & Bm1_20815 & $\begin{array}{l}\text { Embryonic lethal, body morphology defect, larval lethal, sterile, } \\
\text { paralyzed, uncoordinated movement, paralyzed }\end{array}$ \\
\hline & Smp_176990 & lin45_Ce_T & Bm1_40290 & Sterile, osmotic integrity problems \\
\hline \multicolumn{5}{|l|}{ CMGC } \\
\hline & Smp_068960 & F22D6.5_Ce & Bm1_12230 & $\begin{array}{c}\text { Embryonic lethal, slow growth, sterile progeny, uncoordinateed } \\
\text { movement }\end{array}$ \\
\hline & Smp_041770 & spk_1_Ce & - & Embryonic lethal, larval lethal, maternal sterile \\
\hline & Smp_172700 & cdk_4_Ce & - & Locomotion variant, larval lethal, sterile progeny \\
\hline & Smp_133020 & pmk-1_Ce, pmk-2_Ce & - & $\begin{array}{c}\text { Apoptosis increased, sterile progeny, reduced brood size, } \\
\text { embryonic lethal }\end{array}$ \\
\hline & $\begin{array}{l}\text { Smp_134260, Smp_133490, } \\
\text { Smp_133500 }\end{array}$ & C05D10.2 & - & Reduced brood size, embryonic lethal \\
\hline & Smp_080730 & cdk_1_Ce & - & embryonic lethal, sterile progeny \\
\hline & $\begin{array}{l}\text { Smp_155720, Smp_125310, } \\
\text { Smp_008260.1 }\end{array}$ & $\begin{array}{l}\text { Y18D10A.5_Ce, } \\
\text { C44H4.6_Ce }\end{array}$ & - & Larval lethal, slow growth, embryonic lethal \\
\hline & Smp_156990 & F39H11.3_Ce & Bm1_33825 & Sterile \\
\hline & Smp_176620 & $\begin{array}{l}\text { B0495.2_Ce, } \\
\text { ZC504.3_Ce }\end{array}$ & Bm1_17240 & Embryonic lethal \\
\hline & Smp_003000 & H25P06.2_Ce & - & Embryonic lethal, slow growth, uncoordinated movement \\
\hline & Smp_150040 & Cdk_7_Ce & Bm1_14135 & Embryonic lethal \\
\hline & Smp_140700, Smp_074080 & lit_1_Ce & Bm1_130 & Embryonic lethal, larval lethal \\
\hline & Smp_141230 & mbk_2_Ce & Bm1_38345 & Embryonic lethal, sterile progeny \\
\hline
\end{tabular}

Orthology relationships were inferred based on phylogenetic trees. RNAi phenotype for C. elegans were visualized by recent work [68] that relied on identification and analysis of essential genes.

shown by microarray analysis [72,73]. The role of these proteins in the parasite $S$. mansoni is unclear.

\section{Tyrosine kinases}

TK group

PTKs can be classified, based on the presence or absence of transmembrane domains, into receptor tyrosine kinase (RTK) that relay intracellular signals [74], and cytoplasmatic tyrosine kinase (CTK). S. mansoni kinome contains 15 RTKs and 19 CTKs. The 15 RTK include two InsRs (Insulin Receptors), four EGFRs (Epidermal Growth Factor Receptor), two VKRs (Venus Flytrap Kinase Receptors), a representative for Ephs (Ephrin receptors), Ror, CCK4 (Colon Carcinoma Kinase 4), and MUSK (Muscle_Specific kinase) families, besides three unknown receptors. 


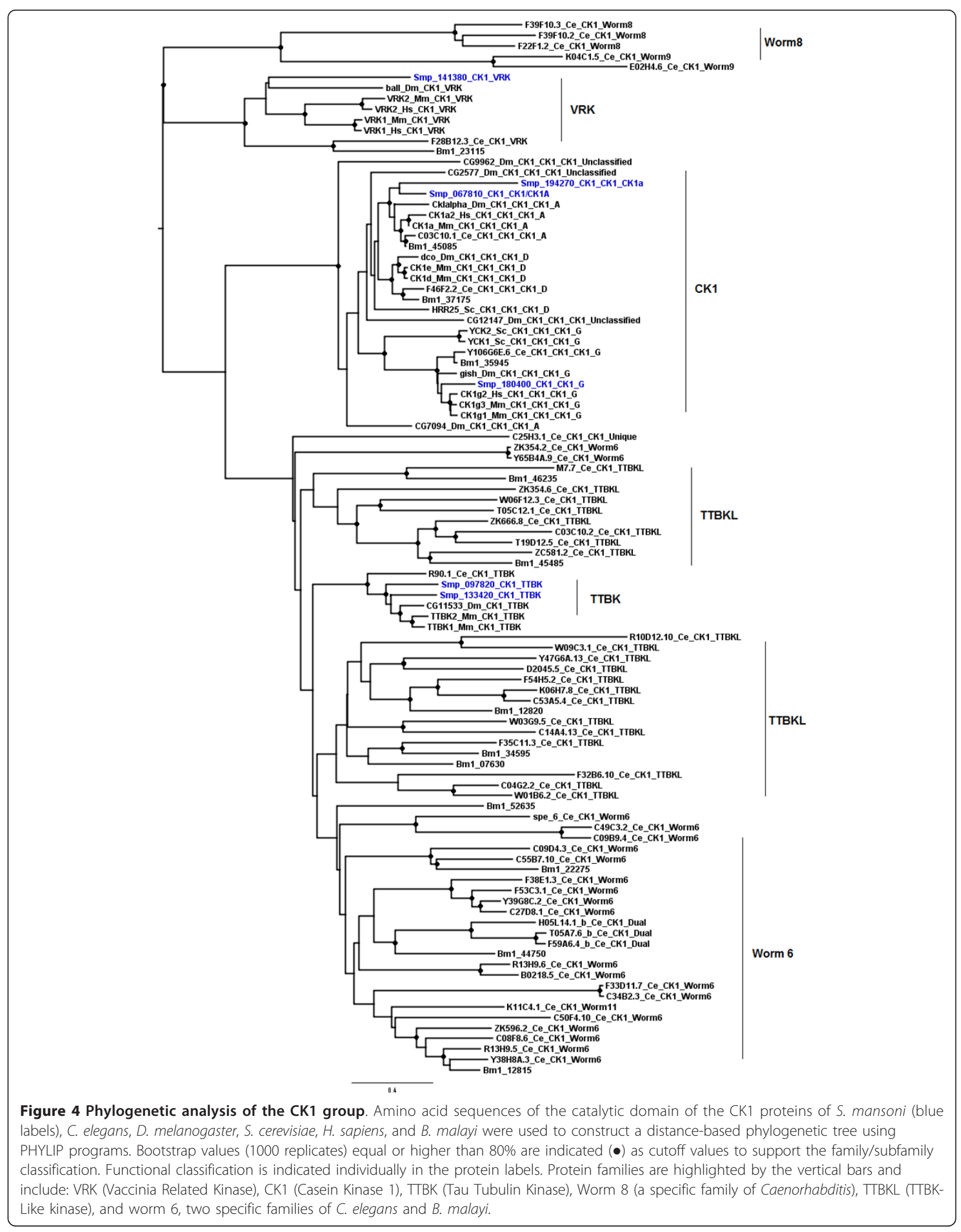


Two InsRs in S. mansoni, SmIR-1 (Smp_009990) and SmIR-2 (Smp_074030) present distinct functions during parasite development. These two receptors are well clustered within the InsR families but showed to be more divergent than the mammalian and $D$. melanogaster proteins (Additional file 7). SmIR-1 was localized in the muscles, intestinal epithelium, and basal membrane of adult male and female worms and at the periphery of schistosomula, mainly in the tegument [75]. SmIR-1 colocalized in schistosome tegument with glucose transporters suggesting a role in the regulation of glucose uptake which is an essential nutrient for the intramammalian stages of S. mansoni. SmIR-2, in contrast, was distributed in the parenchyma of adult males and females indicating a possible involvement of the receptor in parasite growth. S. mansoni is the first invertebrate with two insulin receptors characterized that seem to have distinct functions, as in vertebrates $[18,75,76]$. Mammals have two InsR members; insulin-like growth factor receptor (IGFR), which has a role in controlling growth, and (InR) which has specialized in metabolic regulation [77].

In C. elegans EGFR signaling induces behavioral quiescence [78]. One S. mansoni EGFR homolog (Smp_173590) was localized in the parasite muscle and perhaps related to muscle development or function [79]. Vertebrate EGF activates $S$. mansoni EGFR and the downstream classical ERK pathway (Figure 3), indicating the conservation of EGFR function in S. mansoni [79]. Moreover, human EGF was shown to increase protein and DNA synthesis as well as protein phosphorylation in parasites, supporting the hypothesis that host EGF could regulate schistosome development [80]. The similarity of schistosome proteins to sex hormone receptors of mammalian hosts provides a good example of host parasite relationship, where the adult worm depends on the host hormone synthesis for their maturation and reproduction [3].

Five $S$. mansoni proteins are not clustered with the main RTK families as shown in our phylogenetic analyses (Additional file 7). Three of them have a truncated catalytic domain (Smp_175590, Smp_093500 and Smp_157300) and two are specific RTK with a venus flytrap domain (VKR family). VKR is a family of receptors found in invertebrates, especially in insects. One S. mansoni VKR protein, Smp_153500 (SmVKR), was recently studied [81]. We identified another protein (Smp_019790) clustering with SmVKR (Additional file 7) with a high similarity. Despite the similarity of the catalytic domain of VKR protein with the IRs, these two proteins are not clustered with InsR family. In this respect, the most interesting finding is that VKR family members are not found in mammals and could represent good targets for drug development as a specific inhibitor for this family will probably not affect any protein of the host [81].
The CTKs in S. mansoni are represented by 11 different families (Additional file 7). SmTK3 (Smp_054500) and SmTK5 (Smp_136300) - src family members, and SmTK4 (Smp_149460) - syk family, are present in reproductive organs and possibly involved in the development of gonads and multiplication of germinal and vitelline cells [82-84]. Abl proteins of S. mansoni (Smp_128790 and Smp_169230) were recently studied using a Abl specific inhibitor (Imatinib, Gleevac ${ }^{\circledR}$ ). The results showed an important morphological alteration in adult worms of $S$. mansoni that led to the death of the parasites [21]. C. elegans contains 42 members of the Fer family, while only a single member, SmFes, was found in S. mansoni. The Fer gene of S. mansoni (SmFes, Smp_164810) exhibits the characteristic features of Fes/Fps/Fer (fes, feline sarcoma; fps, Fujinami poultry sarcoma; fer, fes related) PTKs. By immunolocalization assays it was shown that SmFes is particularly expressed at the terebratorium of miracidia and tegument of cercaria and schistosomula skin-stage. These findings suggest that SmFes may play a role in signal transduction pathways involved in larval transformation after penetration into intermediate and definitive hosts $[85,86]$.

\section{RGC group}

Proteins in this group share sequence similarity to the catalytic domain (Pfam: PF07714) found in proteins of the TK group [87]. The RGC group is underrepresented in most species, except in C. elegans that has a large expansion of these proteins and $S$. cerevisiae that has no protein with similarity to the TK catalytic domain (Figure 2). Only three RGC members were identified in the $S$. mansoni ePKinome. All of them are more closely related to the mammalian and insect families than the worm family. C. elegans and B. malayi RGC proteins form at least two different families noticeably more divergent from $S$. mansoni, D. melanogaster, M. musculus, and $H$. sapiens families as suggested by our phylogenetic analysis (Additional file 8). Most RGC proteins remain functionally uncharacterized. In C. elegans, several RGC proteins are highly expressed in restricted sets of neurons and are implicated in chemosensation. One RGC is involved in dauer stage formation [88]. Other parasites such as L. major, T. brucei, T. cruzi and P. falciparum also lack homologs in the RGC group $[20,89]$. The three S. mansoni RGC proteins have an amino acid substitution in the aspartic acid in subdomain VIb of the catalytic domain, rendering them catalytically inactive. Although the catalytic center of an enzyme is usually highly conserved, there have been reports of proteins, like those of the RGC group of ePKs, with substitutions at essential catalytic positions, which convert the enzyme into a catalytically inactive form. A recent study showed that inactive enzymes are found in a large variety of families conserved among metazoan species and they have lost their catalytic activity, 
have adopted new functions, and are involved in regulatory processes $[34,90]$.

\section{Hybrid protein kinase TKL Group}

TKL consists of a divergent group that is phylogenetically close to the tyrosine kinases (Figure 3). However, TKL proteins have an unusual catalytic domain that is a hybrid between the serine/threonine and tyrosine kinases [32]. The catalytic domain may display greater similarity to the tyrosine catalytic domain (Pfam: PF07714) or to the serine/threonine catalytic domains (Pfam: PF00069) [10,11]. In S. mansoni, the TKL group includes MLK (Miked Lineage Kinases), LISK (Family containing closely related LIMK and TESK sub-families), Raf, RIPK (Receptor Interacting Protein Kinase), STKR (Serine/threonine kinase Receptors for activin and TGF $\beta$ ligands), and LRRK (Leucine Rich Repeat Kinase) (type 1 and type 2) families. Of the 19 TKL proteins found in S. mansoni, 15 display greater similarity to the serine/threonine catalytic domain and four (of Raf and MKL/ILK families) to the tyrosine catalytic domain. S. mansoni has no homologous proteins of the IRAK (interleukin-1 (IL-1) receptor-associated kinase) family that is present in C. elegans, $B$. malayi, D. melanogaster, Homo sapiens, and M. musculus (Additional file 9). Although S. cerevisiae does not have any TKL protein homologue, other fungal species do contain such proteins [14]. Raf (also known as MAPKKK) is a TKL family that plays an important role in the activation of STE proteins in the signaling cascade that culminates in the activation of ERK1/2 (Figure 4) [63]. A recent study showed that blocking the expression of the homolog of the S. mansoni Raf protein (Smp_176990) in C. elegans by RNAi, generate a sterile phenotype, which supports the hypothesis of the involvement of Raf protein in the germline development, somatic gonad development, oogenesis, spermatogenesis, ovulation or fertilization (Table 2). Raf protein may represents a good target for drug development in S. mansoni.

A STKR member that binds to TGF $\beta$ (Transforming growth factor) is a membrane receptor that can be divided into two subclasses (Type I and Type II). The type II receptor binds TGF $\beta$ and then recruits the type I receptor. The TGF $\beta$ type I receptor was cloned in $S$. mansoni (SmTßRI - Smp_173400.2) and it was found to be localized in the parasite surface [91,92]. Other type I STRK (Smp_049760) was identified in the S. mansoni predicted proteome and was not experimentally characterized so far (Additional file 9). Three type II STKRs (TGF $\beta$ type II receptors) are proteins identified in the same contig which were predicted to be a product of alternative splicing. A recent study revealed the presence of two transcripts that are translated into two different isoforms of type II receptor [93]. These transcripts are produced from the same gene by alternative splicing of the last two exons. The authors indicated that these different type II receptors might signal in different cells or development stages. Furthermore, that study showed that in the presence of human TGF $\beta$, SmT $\beta$ RII (Smp_165310) activated SmT $\beta R I$. The results also provide evidence for the role for the TGF- $\beta$ signaling pathway in male-induced female reproductive development $[94,95]$.

\section{Other Group}

The Other group consists of a mixed collection of kinases with representatives in higher eukaryotes, including SCY1, NEK (Mitotic Kinase family, also known as NRK), PEK, Haspin, WEE, NAK (Numb-Associated Kinase), ULK (Unc-51 Like Kinase), IRE (Inositol Requiring), PLK (Polo Like Kinases), AUR (Aurora Kinase), and CDC7 (Cell Division Control 7) families (Additional file 1). Our analysis showed that $15 \%$ of the S. mansoni ePKinome do not fall into any of the eight major groups, but include 20 smaller and conserved families.

\section{Accessory Domains}

The structure of the catalytic domain of many ePKs is highly conserved across distinct organisms because of the fact that all ePKs recognize and bind ATP at common sites. However, only the catalytic domain (architecture/sequence) is sufficiently divergent to enable the discrimination of groups, families, and subfamilies (Figure 5).

Most ePKs also have a second domain that is involved in protein-protein interaction and allosteric regulation of the catalytic domain [17]. In this work, only the catalytic domain sequence was used in the phylogenetic analyses. Interestingly, when the information on the ePK accessory domains was integrated into the phylogenies, we observed a correlation between diversity of protein architecture and the phylogenetic patterning. We also believe that the diversification of the ePKs happened a long time ago.

The analysis of the sequence domain data from Pfam [96] showed that approximately $30 \%$ of S. mansoni ePKs are multi-domain proteins containing various regulatory and signaling domains tethered to catalytic kinase domains (Figures 6 and 7). It is known that the distinct protein architectures reflect functional differences among proteins [32]. Hence, understanding the mechanisms that generate such diverse repertoire of protein architectures is essential to the comprehension of the biological function of the ePKs. Furthermore, we observed in ePKs of $S$. mansoni some unusual architecture that probably occurs by domain fusion and recruitment (see some examples 


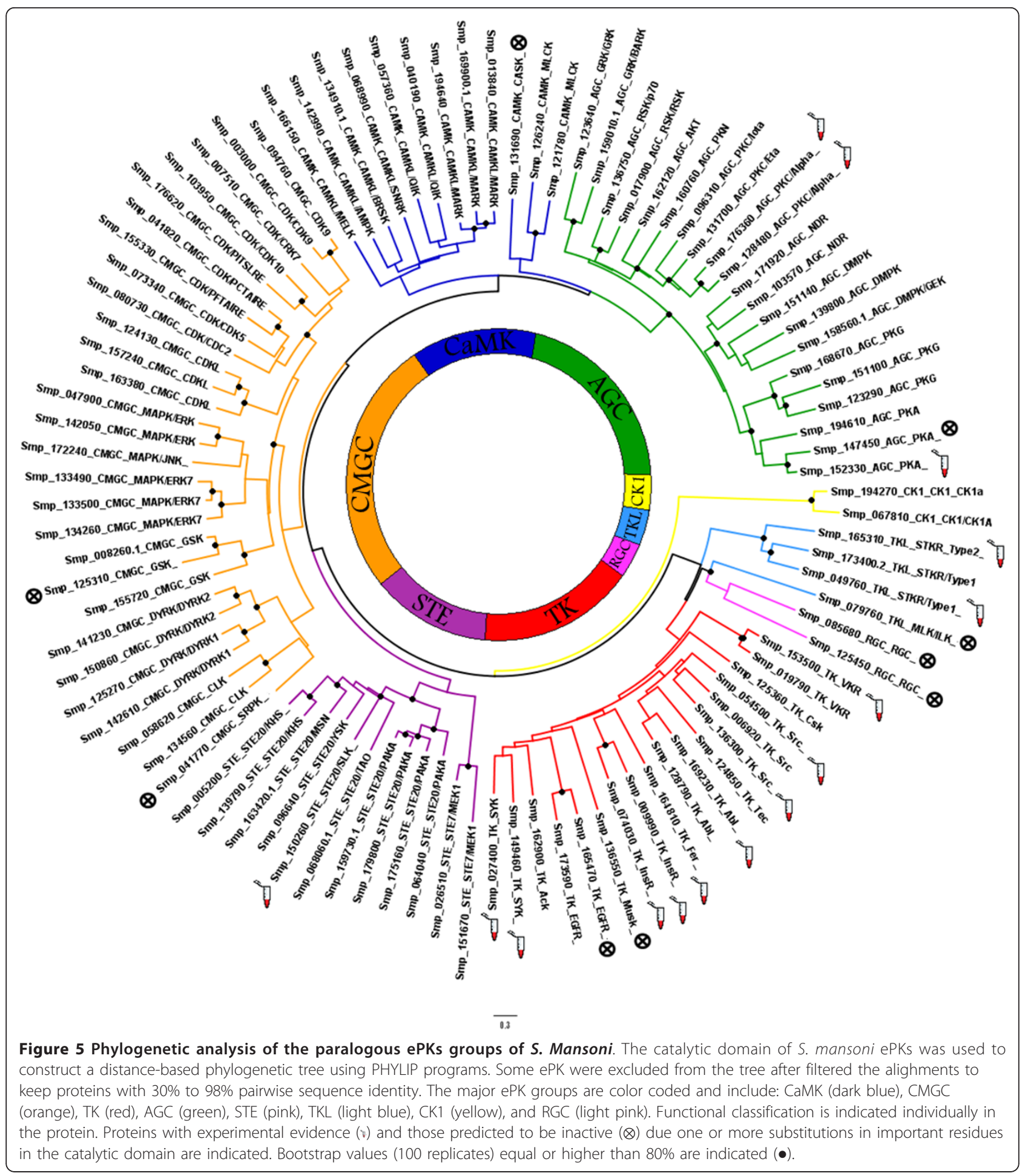

below), generating specificity towards cognate substrates and regulators in this parasite.

The most common Pfam accessory domains found in S. mansoni kinases are Pkinase_C (Pfam: PF00433) all found in the AGC group; C1_1 (Pfam: PF00130) found in the AGC and TKL groups; SH2 (PF00017) all found in the TK group; and SH3 (Pfam: PF00018) found in TK and TKL groups. These domains are commonly found in protein kinase families as we observed in other species from KinBase [15].

More than $40 \%$ of $S$. mansoni AGC group have the PKinase_C domain associated with the catalytic domain. The 


\section{Serine/Threonine Kinase}
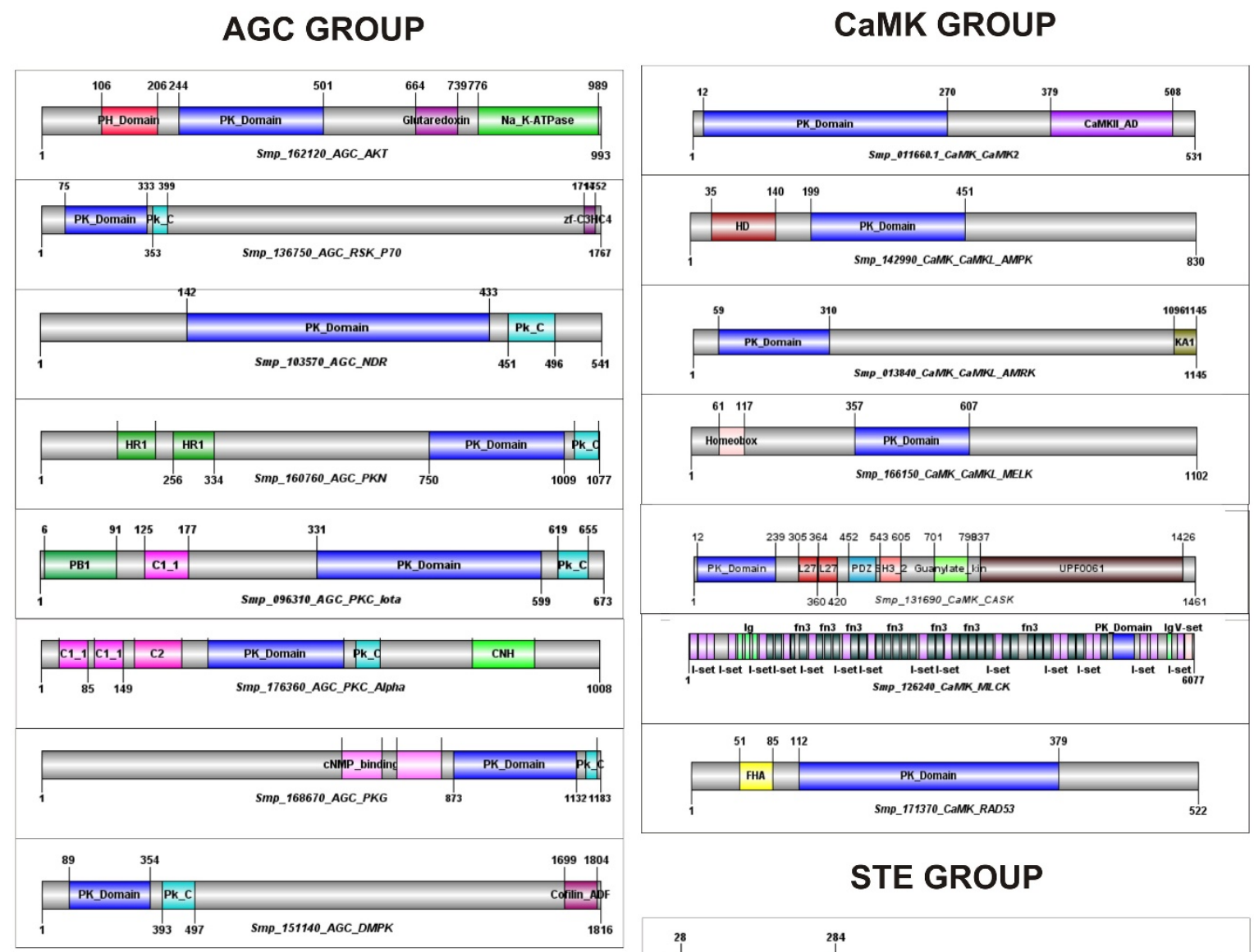

CaMK GROUP

\section{STE GROUP}

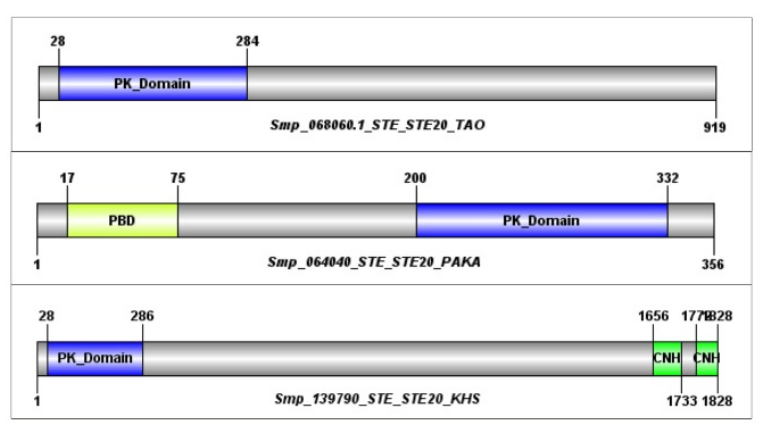

Figure 6 S. mansoni ePKs domain architectures. Representative domain organizations of some S. mansoni ePKs belonging to the AGC, CaMK, CK1, CMGC, and STE groups are shown. Each protein ID and classification is shown below each image. Abbreviations followed are: PK_Domain (Protein kinase domain), PH_Domain (Pleckstrin Homology domain), Na_K_ATPase (Sodium/potassium ATPase beta chain), PK_C- (Protein Kinase C terminal domain), Zf-C3HC4 (zinc-finger, C3HC4 type RING finger), HR1 (Hr1 repeat), PB1 (Phox and Bem1p domain), C1_1 (Phorbol esters/ diacylglycerol binding domain), C2 (Ca ${ }^{2+}$-dependent domain), CNH (citron homology domain), cNMP_binding (cyclic nucleotide-binding domain), Cofilin_ADF (Cofilin/tropomyosin-type actin-binding protein), CaMKII_AD (Calcium/calmodulin dependent protein kinase II Association), HD (HD homeobox domain), L27 (L27 domain), PDZ (PDZ domain, also known as DHR or GLGF), SH3_2 (Variant SH3 domain), Guanylate_kin (Guanylate kinase), UPF0061 (Uncharacterized ACR, YdiU/UPF0061 family), Ig (Immunoglobulin domain), fn3 (Fibronectin type III domain), V-set (Immunoglobulin V-set domain), FHA (Forkhead-associated domain), and PBD (P21-Rho-binding domain). The protein domain architectures were generated using DOG 1.0 [111] based on the Pfam domain limits [96]. 


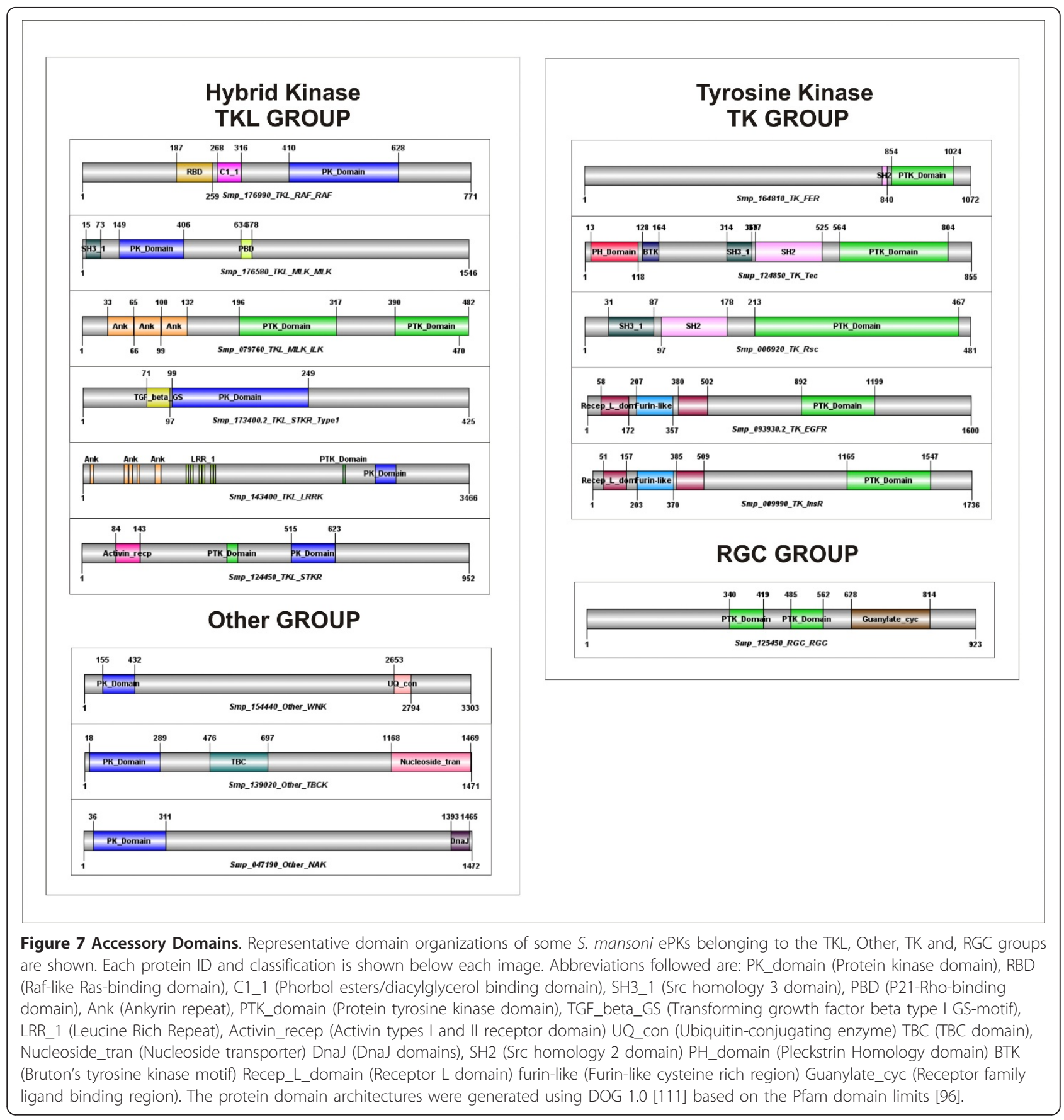

C1_1 domain is conserved in N-terminal regions of all PKC proteins of S. mansoni (Figure 6) and has been shown to bind PE (phorbol esters) and DAG (diacylglycerol). DAG is an important second messenger and Phorbol esters are analogues of DAG $[32,96]$. The C1_1 domain is present in one or two copies depending on the isozyme of PKC (Figure 6). cNMP_binding is a N-terminal domain of PKG proteins that bind cyclic nucleotides (cAMP or cGMP) to relieve the inhibition of the catalytic domain [15,35]. The AKT protein of $S$. mansoni
(Smp_162120) has an unusual domain combination (Figure 6) as the two C-terminal domains (Glutaredoxin and $\mathrm{Na}_{-} \mathrm{K}$-ATPase) are not found in $D$. melanogaster, $C$. elegans, M. musculus and $H$. sapiens.

CASK is a member of the CaMK group and plays a key role in establishing inter-cellular contacts and plasticity at cellular junctions [54]. The accessory domains found in S. mansoni CASK protein (L27 and PDZ domains, which serve as protein interaction modules, $\mathrm{SH} 3$, and a C-terminal guanylate kinase domains) are 
conserved in higher eukaryotes. However, the UPF0061 (Pfam: PF02696) is uncharacterized [96] and possesses an unusual domain found in the C-terminal region of $S$. mansoni CASK protein (Figure 6). The long protein kinase MLCK (Figure 5a) possesses a large number of Ig repeats (I-set, V-set and Ig) that, in other species, are involved in a variety of functions, including cell-cell recognition, cell-surface receptors, muscle structure and the immune system [96], and fn3 repeats, that is an approximately 100 amino acid domain commonly found in a variety of organisms.

The CMGC and CK1 groups have none or a few accessory domains in S. mansoni. However, it is known that small regions in these proteins play an important role in recognizing and binding to the substrate $[97,98]$. For example, the $\mathrm{CD}$ domain (common docking domain) is a C-terminal region of MAPK proteins composed of a set of negatively charged amino acids that is used to anchor protein activators (such as STE proteins), substrates (such as MAPKAPK) and inactivating proteins (such as MAPK phosphatases) [99]. Thus, this region governs a series of signal transduction in the cascade of reactions of MAPKs. Other regions, including the ED (ERK docking) site, working with the $C D$ domain and ensuring specificity and interaction strength [99].

PBD (p21-Rho-binding) and C-terminal $\mathrm{CNH}$ domain are usually found in the STE20 families (Figure 6). PBD binds to cdc42-GTPases activating the signaling cascade which act upstream in the MAPK cascade. The $\mathrm{CNH}$ domain interacts with the small GTPase and regulating the actin cytoskeleton [96].

The SH3 and SH2 (Pfam: PF00018 and PF00017, respectively) domains are common found in CTK proteins. $\mathrm{SH} 2$ function as regulatory modules of intracellular signaling cascades and it was found in eight out of 19 S. mansoni CTKs. Fer PTK is usually composed of three domains, $\mathrm{FHC}$ domain, $\mathrm{SH} 2$, and C-terminal kinase domain as it occurs in Fer proteins of H. sapiens, M. musculus, and D. melanogaster. However, the $S$. mansoni Fer protein (SmFes - Smp_164810) [86] and the 42 Fer proteins of C. elegans seems to have lost the N-terminal FHC domain (Figure 7). RTKs are characterized by an extracellular domains, a membrane spanning segment and an intracellular kinase domain [32]. The extracellular ligand binding domain of EGFR and InsR proteins are composed of two receptor_L sandwiching a Furin_like domain (Figure 7). SmVKR is composed of an unusual extracellular Venus flytrap module (VFT) linked through a single transmembrane domain to an intracellular tyrosine catalytic domain similar to that of the insulin receptor and a putative function in reproduction and development was observed [81]. Other extracellular domains found in S. mansoni are Ephrin_Ibd (Pfam: PF01404) in the Ephrin recptors (Eph) and Ig domains (Pfam: PF00047) in CCK4 proteins (Additional file 1).

In conclusion, the protein architecture, including the accessory domains, may indicate potential protein partners. Signaling roles of schistosome specificities or unusual architectures are of special biological interest.

\section{Conclusions}

This study allowed us to identify and classify $252 \mathrm{ePKs}$ encoded in the predicted proteome of S. mansoni. Together, these proteins represent $1.9 \%$ of the proteome and indicate that protein phosphorylation is an important mechanism for regulating the complex life cycle of the parasite. We improve the functional annotation of $40 \%$ of S. mansoni ePKs (Table 3) by applying a phylogenetic framework. Moreover, it was possible to gain insights into kinase function once $94 \%$ of the $S$. mansoni ePKinome had previously an unknown function. S. mansoni has proteins in each ePKs group. Most of them are clearly clustered with known kinases from other eukaryotes with no family being exclusively found or expanded in $S$. mansoni. Some proteins are not clustered with the main ePK family as the catalytic domain is truncate, indicating that the current gene/protein predictions require further refinement. Proteins were mentioned as potential targets for drug design and development as they may play an essential function in the parasite. Furthermore new and effective drugs bind PKs close but not in the ATP site and occlude ATP access to the kinase to retard enzyme activity [17]. So, proteins of $S$. mansoni with a sequence highly similar to host proteins can be used as protein

Table 3 S. mansoni ePKinome annotation improved by phylogenomics

\begin{tabular}{lll}
\hline & After phylogenetic analysis & \\
\hline Modifications & Number of changes & \% of S. mansoni ePKinome \\
\hline Change group classification & 14 & $5,55 \%$ \\
Change family classification & 18 & $7,14 \%$ \\
Add subfamily & 61 & $24,20 \%$ \\
Classification of unknown proteins & 11 & $3,96 \%$ \\
\hline Total of changes & $\mathbf{1 0 4}$ & $\mathbf{4 0 , 8 5 \%}$
\end{tabular}

Through phylogenetic analysis, we have improved the functional annotation of $40 \%$ of S. mansoni ePKs by changing protein classification at the group and family levels, assigning subfamilies, and classifying proteins without any previous classification. 
targets since the inhibitor binds in non-conserved residues outside the ATP site. Also, the unusual domains found in S. mansoni can be used for constructing more specific $S$. mansoni inhibitors. Moreover, as we continue this work, we will highlight the biochemical and physiological adaptations of $S$. mansoni in response to diverse environments during parasite development, vector interaction, and host infection.

\section{Methods}

\section{Organisms and Sequences}

S. mansoni [NCBI taxid: 6183] and six other organisms were selected for this work including Homo sapiens [taxid: 9606], Mus musculus [taxid: 10090], Drosophila melanogaster [taxid: 7227], Caenorhabditis elegans [taxid: 6239], Brugia malayi [taxid: 6279], and Saccharomyces cerevisiae [taxid: 4932]. The S. mansoni predicted proteome data was downloaded from SchistoDB, version [2.0] [29], which contains the original gene and genomic information provided by the Wellcome Trust Institute and described elsewhere [26]. Datasets of protein kinases from the other organisms were downloaded from the kinase database at Sugen/Salk - KinBase [15], except for Brugia malayi, which was retrieved from KEGG [100].

\section{Functional Classification}

Functional classification of protein kinases into groups, families, and subfamilies followed the proposed hierarchy described elsewhere $[12,13,32]$. Potential protein kinases of $S$. mansoni were identified and characterized by combined approaches based on sequence similarity and phylogenetic relationships. These proteins were first identified by similarity to Hidden Markov Models (HMMs) as described below. Also based on sequence similarity, each predicted protein kinase was manually annotated by integrating data from InterProScan [101] and reverse PSI-BLAST (rpsblast) [102] output searches into Artemis [103]. Further analysis was performed by HMMs searching for non-catalytic (accessory) domains associated to the conserved catalytic domain of protein kinases based on data available at the Protein families database - Pfam [96]. Functional classification was also devised based on the literature and on the assumption of a broad conservation of the molecular functions. Phylogenetic analyses of the ePK kinases groups performed in the present work corroborated this classification as well as supported new functional assignments for previously uncharacterized proteins (see below).

\section{Hidden Markov Models}

In order to identify potential homologs in S. mansoni, amino acid sequences of known protein kinases of five model organisms (H. sapiens, M. musculus, D. melanogaster, C. elegans, and S. cerevisiae) were selected. A total of 68 diverse amino acid sequences corresponding to the kinase catalytic domain and sharing less than 50\% sequence identity were aligned in MAFFT [30] and manually-edited for further analysis. Local and global HMMs were built with the HMMer package http:// hmmer.janelia.org from multiple sequence alignments and used for sensitive searches against the S. mansoni proteome [26].

\section{Phylogenetic Analyses}

Amino acid sequences corresponding to the conserved catalytic domain (Pfam: PF0069 or PF07714) of each group of protein kinases were separately aligned using the default parameters of MAFFT [30]. Multiple sequence alignments were filtered to keep proteins sharing $50 \%$ to $90 \%$ pairwise sequence identity using the decreased redundancy tool [104] and manually edited to remove ambiguous regions using BioEdit [105]. Final alignments were used in phylogenetic reconstructions through multiple programs available in the Phylogeny Inference Package PHYLIP, version 3.69 [31]. Initially, 1000 random datasets (replicates) were created for each alignment using seqboot with default parameters. For each dataset, it was calculated a distance matrix under the JTT model with gamma-distributed sites by protdist. Next, phylogenies were estimated from distance matrix data adopting the Fitch-Margoliash criterion as implemented in fitch. Finally, the results from the random datasets were summarized by consense, which computes consensus trees by the majority-rule consensus tree method. Phylogenetic trees were visualized and edited using the Tree Figure Drawing Tool - FigTree, version 1.3.1 [106]. Nodes with at least $80 \%$ bootstrap values were considered to support functional prediction.

\section{Additional material}

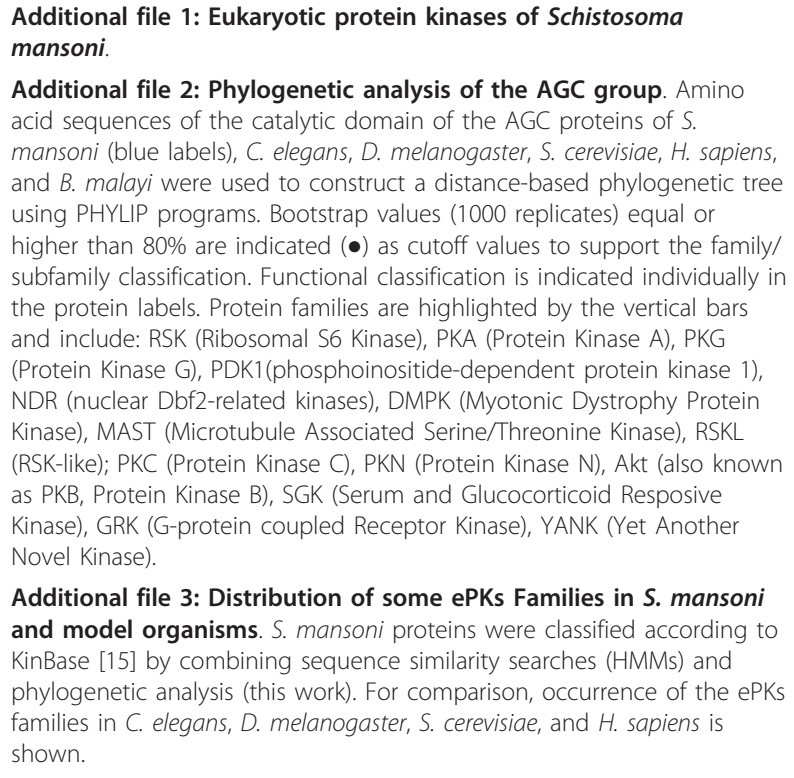

Additional file 3: Distribution of some ePKs Families in S. mansoni and model organisms. S. mansoni proteins were classified according to KinBase [15] by combining sequence similarity searches (HMMs) and phylogenetic analysis (this work). For comparison, occurrence of the ePKs families in C. elegans, D. melanogaster, S. cerevisiae, and H. sapiens is shown. 
Additional file 4: Phylogenetic analysis of the CaMK group. Amino acid sequences of the catalytic domain of the CaMK proteins of $S$. mansoni (blue labels), C. elegans, D. melanogaster, S. cerevisiae, H. sapiens, and $B$. malayi were used to construct a distance-based phylogenetic tree using PHYLIP programs. Bootstrap values (1000 replicates) equal or higher than $80 \%$ are indicated $(\bullet)$ as cutoff values to support the family/ subfamily classification. Functional classification is indicated individually in the protein labels. Protein families are highlighted by the vertical bars and include: MAPKAPK (MAP Kinase Associated Protein Kinase), CAMK1 (CAMK family 1), PHK (Phosphorylase Kinase), Trio, DAPK (Death Associated Protein Kinase), MLCK (Myosin Light Chain Kinases), CASK, CAMK2 (CAMK family 2), DCAMKL (Doublecortin and CaMK-Like), PKD (Protein Kinase D), RAD53, Trbl, CAMKL (CAMKL-like).

Additional file 5: Phylogenetic analysis of the CMGC group. Amino acid sequences of the catalytic domain of the CMGC proteins of $S$. mansoni (blue labels), C. elegans, D. melanogaster, S. cerevisiae, H. sapiens, and $B$. malayi were used to construct a distance-based phylogenetic tree using PHYLIP programs. Bootstrap values (1000 replicates) equal or higher than $80 \%$ are indicated $(\bullet)$ as cutoff values to support the family/ subfamily classification. Functional classification is indicated individually in the protein labels. Protein families are highlighted by the vertical bars and include: GSK (Gycogen Synthase 3 Kinase), MAPK (Mitogen Activated Protein Kinase), CK2 (Cell Kinase 2), CDKL (Cyclin Dependent Kinase Like), CDK (Cyclin Dependent Kinase), SRPK (SR Protein Kinase; phosphorylates SR splicing factors), DYRK (Dual-specificity Y (tyrosine) Regulated Kinase), CLK (CDC-Like Kinase).

Additional file 6: Phylogenetic analysis of the STE group. Amino acid sequences of the catalytic domain of the STE proteins of S. mansoni (blue labels), C. elegans, D. melanogaster, S. cerevisiae, H. sapiens, and B. malayi were used to construct a distance-based phylogenetic tree using PHYLIP programs. Bootstrap values (1000 replicates) equal or higher than $80 \%$ are indicated $(\bullet$ ) as cutoff values to support the family/subfamily classification. Functional classification is indicated individually in the protein labels. Protein families are highlighted by the vertical bars and include: STE11 (MAP3K (MAP kinase kinase kinase) genes), STE20 (MAP4K (MAP kinase kinase kinase kinase) genes), STE7 (MAP2K (MAP kinase kinase) genes).

Additional file 7: Phylogenetic analysis of the TK group. Amino acid sequences of the catalytic domain of the TK proteins of S. mansoni (blue labels), C. elegans, D. melanogaster, S. cerevisiae, H. sapiens, and B. malayi were used to construct a distance-based phylogenetic tree using PHYLIP programs. Bootstrap values (1000 replicates) equal or higher than $80 \%$ are indicated $(\bullet)$ as cutoff values to support the family/subfamily classification. Functional classification is indicated individually in the protein labels. Protein families are highlighted by the vertical bars and include: JAK, Ack (Activated Cdc42-associated tyrosine kinase), Syk, FAK (Focal Adhesion Kinase), VKR, Fer, Sev, ALK (Anaplastic Lymphoma Kinase), InsR (Insulin Receptor), DDR (Discoidin Domain Receptor kinase), Musk (Muscle-Specific Kinase), Ror, Lmr (Lemur Kinase), Eph (Ephrin receptors), AxI (Also known as TAM (Tyro3, Axl, Mer)), Ryk, EGFR (Epidermal Growth Factor Receptor), FGFR (Fibroblast Growth Factor Receptor), PDGFR, VEGFR, Kin16, Jak (Janus Kinases), Tec, Abl (Abelson murine leukemia homolog), and Src.

Additional file 8: Phylogenetic analysis of the RGC group. Amino acid sequences of the catalytic domain of the RGC proteins of $S$. mansoni (blue labels), C. elegans, D. melanogaster, S. cerevisiae, H. sapiens, and $B$. malayi were used to construct a distance-based phylogenetic tree using PHYLIP programs. Bootstrap values (1000 replicates) equal or higher than $80 \%$ are indicated $(\bullet)$ as cutoff values to support the family/ subfamily classification. Functional classification is indicated individually in the protein labels.

Additional file 9: Phylogenetic analysis of the TKL group. Amino acid sequences of the catalytic domain of the CK1 proteins of S. mansoni (blue labels), C. elegans, D. melanogaster, S. cerevisiae, H. sapiens, and B. malayi were used to construct a distance-based phylogenetic tree using PHYLIP programs. Bootstrap values (1000 replicates) equal or higher than $80 \%$ are indicated $(\bullet)$ as cutoff values to support the family/subfamily classification. Functional classification is indicated individually in the protein labels. Protein families are highlighted by the vertical bars and include: IRAK (IL1 Receptor Associated Kinase), RIPK (Receptor Interacting Protein Kinases), LISK (Family containing closely related TESK and LIMK sub-families), MLK (Miked Lineage Kinases), LRRK (Leucine Rich Repeat Kinase), RAF, STKR (Serine/Threonine Kinase Receptors - receptors for activin and TGFb ligands).

\section{Abbreviations}

ATP: adenosine triphosphate; CAMP: cyclic adenosine monophosphate; GTP: guanosine triphosphate; NCBI: National Center for Biotechnology Information; RNAi: RNA interference.

\section{Acknowledgements}

This work was funded by the National Institutes of Health - NIH/Fogarty International Center (PPM-00439-10 to GO), Secretaria de Ciência, Tecnologia e Ensino Superior de Minas Gerais, Fundação de Amparo à Pesquisa do Estado de Minas Gerais, SECTES/FAPEMIG, Brazil (CBB-1181/08 and PPM00439-10 to GO), and Conselho Nacional de Desenvolvimento Científico e Tecnológico - CNPq (CNPq-Universal 476036/2010-0 to LAN, CNPq-INCT 573839/2008-5 to GO, and INCT-DT 573839/2008-5 to GO). LFA is a fellow of FIOCRUZ. The authors acknowledge the use of the computing resources of the Center for Excellence in Bioinformatics, CEBio/FIOCRUZ, Brazil.

\section{Author details}

'Genomics and Computational Biology Group, Instituto Nacional de Ciência e Tecnologia em Doenças Tropicais, Centro de Pesquisas René Rachou, Fundação Oswaldo Cruz - FIOCRUZ, Belo Horizonte, MG- 30190-002, Brazil. ${ }^{2}$ Centro de Excelência em Bioinformática, Fundação Oswaldo Cruz FIOCRUZ, Belo Horizonte, MG- 30190-110, Brazil. 3Instituto de Ciências Biológicas, Universidade Federal de Minas Gerais - UFMG, Belo Horizonte, MG- 31270-910, Brazil.

\section{Authors' contributions}

LFA: carried out the functional annotation and phylogenetic studies, and drafted the manuscript. LAN: designed the phylogenetic studies, performed preliminary phylogenetic studies, coordinated the functional prediction, and co-wrote this manuscript. LGAV and LLS carried out the functional annotation based on sequence similarity search using HMMs. AZ wrote the Perl scripts for data manipulation and provided computational support for this study. JCR designed and performed the HMMs analysis. GO participated in the design and coordination of this study, and co-wrote the manuscript. All authors read and approved the final manuscript.

Received: 23 November 2010 Accepted: 6 May 2011 Published: 6 May 2011

\section{References}

1. Haas W, Schmitt R: Characterization of chemical stimuli for the penetration of Schistosoma mansoni cercariae. I. Effective substances, host specificity. Z Parasitenkd 1982, 66:293-307.

2. Haas W, Diekhoff D, Koch K, Schmalfuss G, Loy C: Schistosoma mansoni cercariae: stimulation of acetabular gland secretion is adapted to the chemical composition of mammalian skin. J Parasitol 1997, 83:1079-1085.

3. Han ZG, Brindley PJ, Wang SY, Chen Z: Schistosoma genomics: new perspectives on schistosome biology and host-parasite interaction. Annu Rev Genomics Hum Genet 2009, 10:211-240.

4. Kunz W: Schistosome male-female interaction: induction of germ-cell differentiation. Trends Parasitol 2001, 17:227-231.

5. LoVerde PT, Hirai H, Merrick JM, Lee NH, El-Sayed N: Schistosoma mansoni genome project: an update. Parasitol Int 2004, 53:183-192.

6. Fitzpatrick JM, Johnston DA, Williams GW, Williams DJ, Freeman TC Dunne DW, Hoffmann KF: An oligonucleotide microarray for transcriptome analysis of Schistosoma mansoni and its application/use to investigate gender-associated gene expression. Mol Biochem Parasitol 2005, 141:1-13.

7. Waisberg M, Lobo FP, Cerqueira GC, Passos LK, Carvalho OS, Franco GR, ElSayed NM: Microarray analysis of gene expression induced by sexual contact in Schistosoma mansoni. BMC Genomics 2007, 8:181. 
8. Waisberg M, Lobo FP, Cerqueira GC, Passos LK, Carvalho OS, El-Sayed NM, Franco GR: Schistosoma mansoni: Microarray analysis of gene expression induced by host sex. Exp Parasitol 2008, 120:357-363.

9. Hanks SK, Quinn AM, Hunter T: The protein kinase family: conserved features and deduced phylogeny of the catalytic domains. Science 1988, 241:42-52.

10. Manning G, Plowman GD, Hunter T, Sudarsanam S: Evolution of protein kinase signaling from yeast to man. Trends Biochem Sci 2002, 27:514-520.

11. Hanks SK: Genomic analysis of the eukaryotic protein kinase superfamily: a perspective. Genome Biol 2003, 4:111.

12. Hanks SK, Hunter T: Protein kinases 6. The eukaryotic protein kinase superfamily: kinase (catalytic) domain structure and classification. FASEB J 1995, 9:576-596.

13. Manning G, Whyte DB, Martinez R, Hunter T, Sudarsanam S: The protein kinase complement of the human genome. Science 2002, 298:1912-1934

14. Miranda-Saavedra D, Barton GJ: Classification and functional annotation of eukaryotic protein kinases. Proteins 2007, 68:893-914.

15. KinBase: Kinbase - The kinase database at Sugen/Salk. 2010 [http://www. kinase.com/kinbase], 8-8-2009. Ref Type: Electronic Citation.

16. Boyle SN, Koleske AJ: Dissecting kinase signaling pathways. Drug Discov Today 2007, 12:717-724.

17. Eglen RM, Reisine T: The current status of drug discovery against the human kinome. Assay Drug Dev Technol 2009, 7:22-43.

18. Dissous $C$, Ahier A, Khayath N: Protein tyrosine kinases as new potential targets against human schistosomiasis. Bioessays 2007, 29:1281-1288.

19. Naula C, Parsons M, Mottram JC: Protein kinases as drug targets in trypanosomes and Leishmania. Biochim Biophys Acta 2005, 1754:151-159.

20. Ward P, Equinet L, Packer J, Doerig C: Protein kinases of the human malaria parasite Plasmodium falciparum: the kinome of a divergent eukaryote. BMC Genomics 2004, 5:79.

21. Beckmann S, Grevelding CG: Imatinib has a fatal impact on morphology, pairing stability and survival of adult Schistosoma mansoni in vitro. Int J Parasitol 2010, 40:521-526.

22. Doenhoff MJ, Pica-Mattoccia L: Praziquantel for the treatment of schistosomiasis: its use for control in areas with endemic disease and prospects for drug resistance. Expert Rev Anti Infect Ther 2006, 4:199-210.

23. Doenhoff MJ, Cioli D, Utzinger J: Praziquantel: mechanisms of action, resistance and new derivatives for schistosomiasis. Curr Opin Infect Dis 2008, 21:659-667.

24. Melman SD, Steinauer ML, Cunningham C, Kubatko LS, Mwangi IN, Wynn NB, Mutuku MW, Karanja DM, Colley DG, Black CL, Secor WE, Mkoji GM, Loker ES: Reduced susceptibility to praziquantel among naturally occurring Kenyan isolates of Schistosoma mansoni. PLoS Negl Trop Dis 2009, 3:e504.

25. Pica-Mattoccia L, Doenhoff MJ, Valle C, Basso A, Troiani AR, Liberti P, Festucci A, Guidi A, Cioli D: Genetic analysis of decreased praziquantel sensitivity in a laboratory strain of Schistosoma mansoni. Acta Trop 2009, 111:82-85

26. Berriman M, Haas BJ, Loverde PT, Wilson RA, Dillon GP, Cerqueira GC, Mashiyama ST, Al-Lazikani B, Andrade LF, Ashton PD, Aslett MA, Bartholomeu DC, Blandin G, Caffrey CR, Coghlan A, Coulson R, Day TA, Delcher A, DeMarco R, Djikeng A, Eyre T, Gamble JA, Ghedin E, Gu Y, HertzFowler C, Hirai H, Hirai Y, Houston R, Ivens A, Johnston DA, et al: The genome of the blood fluke Schistosoma mansoni. Nature 2009, 460:352-358.

27. Verjovski-Almeida S, DeMarco R, Martins EA, Guimaraes PE, Ojopi EP, Paquola AC, Piazza JP, Nishiyama MY Jr, Kitajima JP, Adamson RE, Ashton PD, Bonaldo MF, Coulson PS, Dillon GP, Farias LP, Gregorio SP, Ho PL, Leite RA, Malaquias LC, Marques RC, Miyasato PA, Nascimento AL, Ohlweiler FP, Reis EM, Ribeiro MA, Sa RG, Stukart GC, Soares MB, Gargioni C, Kawano T, et al: Transcriptome analysis of the acoelomate human parasite Schistosoma mansoni. Nat Genet 2003, 35:148-157.

28. Webster JP, Oliviera G, Rollinson D, Gower CM: Schistosome genomes: a wealth of information. Trends Parasitol 2010, 26:103-106.

29. Zerlotini A, Heiges M, Wang H, Moraes RL, Dominitini AJ, Ruiz JC, Kissinger JC, Oliveira G: SchistoDB: a Schistosoma mansoni genome resource. Nucleic Acids Res 2009, 37:D579-D582.

30. Katoh K, Asimenos G, Toh H: Multiple alignment of DNA sequences with MAFFT. Methods Mol Biol 2009, 537:39-64.

31. Felsenstein J: Mathematics vs. Evolution: Mathematical Evolutionary Theory. Science 1989, 246:941-942.
32. Deshmukh K, Anamika K, Srinivasan N: Evolution of domain combinations in protein kinases and its implications for functional diversity. Prog Biophys Mol Biol 2010, 102:1-15.

33. Aguero F, Al-Lazikani B, Aslett M, Berriman M, Buckner FS, Campbell RK, Carmona S, Carruthers IM, Chan AW, Chen F, Crowther GJ, Doyle MA, HertzFowler C, Hopkins AL, McAllister G, Nwaka S, Overington JP, Pain A, Paolini GV, Pieper U, Ralph SA, Riechers A, Roos DS, Sali A, Shanmugam D, Suzuki T, Van Voorhis WC, Verlinde CL: Genomic-scale prioritization of drug targets: the TDR Targets database. Nat Rev Drug Discov 2008, 7:900-907.

34. Boudeau J, Miranda-Saavedra D, Barton GJ, Alessi DR: Emerging roles of pseudokinases. Trends Cell Biol 2006, 16:443-452.

35. Taylor SS, Buechler JA, Yonemoto W: CAMP-dependent protein kinase: framework for a diverse family of regulatory enzymes. Annu Rev Biochem 1990, 59:971-1005

36. Donald RG, Allocco J, Singh SB, Nare B, Salowe SP, Wiltsie J, Liberator PA: Toxoplasma gondii cyclic GMP-dependent kinase: chemotherapeutic targeting of an essential parasite protein kinase. Eukaryot Cell 2002, 1:317-328

37. Gurnett AM, Liberator PA, Dulski PM, Salowe SP, Donald RG, Anderson JW, Wiltsie J, Diaz CA, Harris G, Chang B, rkin-Rattray SJ, Nare B, Crumley T Blum PS, Misura AS, Tamas T, Sardana MK, Yuan J, Biftu T, Schmatz DM: Purification and molecular characterization of CGMP-dependent protein kinase from Apicomplexan parasites. A novel chemotherapeutic target. J Biol Chem 2002, 277:15913-15922.

38. Diaz CA, Allocco J, Powles MA, Yeung L, Donald RG, Anderson JW, Liberator PA: Characterization of Plasmodium falciparum CGMPdependent protein kinase (PfPKG): antiparasitic activity of a PKG inhibitor. Mol Biochem Parasitol 2006, 146:78-88.

39. Knockaert M, Gray N, Damiens E, Chang YT, Grellier P, Grant K, Fergusson D, Mottram J, Soete M, Dubremetz JF, Le RK, Doerig C, Schultz P, Meijer L: Intracellular targets of cyclin-dependent kinase inhibitors: identification by affinity chromatography using immobilised inhibitors. Chem Biol 2000, 7:411-422.

40. Swierczewski BE, Davies SJ: A schistosome cAMP-dependent protein kinase catalytic subunit is essential for parasite viability. PLoS Negl Trop Dis 2009, 3:e505.

41. Mellor $\mathrm{H}$, Parker PJ: The extended protein kinase $\mathrm{C}$ superfamily. Biochem $J$ 1998, 332(Pt 2):281-292.

42. Parker PJ, Murray-Rust J: PKC at a glance. J Cell Sci 2004, 117:131-132.

43. Eckert JJ, McCallum A, Mears A, Rumsby MG, Cameron IT, Fleming TP: Specific PKC isoforms regulate blastocoel formation during mouse preimplantation development. Dev Biol 2004, 274:384-401.

44. Gallicano Gl, Yousef MC, Capco DG: PKC-a pivotal regulator of early development. Bioessays 1997, 19:29-36.

45. Steinhart R, Kazimirsky G, Okhrimenko H, Ben-Hur T, Brodie C: PKCepsilon induces astrocytic differentiation of multipotential neural precursor cells. Glia 2007, 55:224-232.

46. Bahia D, Avelar LG, Vigorosi F, Cioli D, Oliveira GC, Mortara RA: The distribution of motor proteins in the muscles and flame cells of the Schistosoma mansoni miracidium and primary sporocyst. Parasitology 2006, 133:321-329.

47. Bahia D, Avelar L, Mortara RA, Khayath N, Yan Y, Noel C, Capron M, Dissous C, Pierce RJ, Oliveira G: SmPKC1, a new protein kinase C identified in the platyhelminth parasite Schistosoma mansoni. Biochem Biophys Res Commun 2006, 345:1138-1148.

48. Ludtmann MH, Rollinson D, Emery AM, Walker AJ: Protein kinase C signalling during miracidium to mother sporocyst development in the helminth parasite, Schistosoma mansoni. Int I Parasitol 2009, 39:1223-1233.

49. Gally C, Wissler F, Zahreddine H, Quintin S, Landmann F, Labouesse M: Myosin II regulation during C. elegans embryonic elongation: LET-502/ ROCK, MRCK-1 and PAK-1, three kinases with different roles. Development 2009, 136:3109-3119.

50. Swulius MT, Waxham MN: $\mathrm{Ca}(2+) /$ calmodulin-dependent protein kinases. Cell Mol Life Sci 2008, 65:2637-2657.

51. Plowman GD, Sudarsanam S, Bingham J, Whyte D, Hunter T: The protein kinases of Caenorhabditis elegans: a model for signal transduction in multicellular organisms. Proc Natl Acad Sci USA 1999, 96:13603-13610

52. Capes-Davis A, Tolhurst O, Dunn JM, Jeffrey PL: Expression of doublecortin (DCX) and doublecortin-like kinase (DCLK) within the developing chick brain. Dev Dyn 2005, 232:457-467. 
53. Lin PT, Gleeson JG, Corbo JC, Flanagan L, Walsh CA: DCAMKL1 encodes a protein kinase with homology to doublecortin that regulates microtubule polymerization. J Neurosci 2000, 20:9152-9161

54. Lehtonen S, Ryan JJ, Kudlicka K, lino N, Zhou H, Farquhar MG: Cell junction-associated proteins IQGAP1, MAGI-2, CASK, spectrins, and alpha-actinin are components of the nephrin multiprotein complex. Proc Natl Acad Sci USA 2005, 102:9814-9819.

55. Caffrey CR, Rohwer A, Oellien F, Marhofer RJ, Braschi S, Oliveira G, McKerrow JH, Selzer PM: A comparative chemogenomics strategy to predict potential drug targets in the metazoan pathogen, Schistosoma mansoni. PLoS One 2009, 4:e4413.

56. Bradham CA, Foltz KR, Beane WS, Arnone MI, Rizzo F, Coffman JA, Mushegian A, Goel M, Morales J, Geneviere AM, Lapraz F, Robertson AJ, Kelkar H, Loza-Coll M, Townley IK, Raisch M, Roux MM, Lepage T, Gache C, McClay DR, Manning G: The sea urchin kinome: a first look. Dev Biol 2006, 300:180-193.

57. Kalis AK, Kroetz MB, Larson KM, Zarkower D: Functional genomic identification of genes required for male gonadal differentiation in Caenorhabditis elegans. Genetics 2010, 185:523-535.

58. Dohrmann PR, Sclafani RA: Novel role for checkpoint Rad53 protein kinase in the initiation of chromosomal DNA replication in Saccharomyces cerevisiae. Genetics 2006, 174:87-99.

59. Noselli S: JNK signaling and morphogenesis in Drosophila. Trends Genet 1998, 14:33-38.

60. Stronach B, Perrimon N: Activation of the JNK pathway during dorsal closure in Drosophila requires the mixed lineage kinase, slipper. Genes Dev 2002, 16:377-387.

61. Kondoh K, Nishida E: Regulation of MAP kinases by MAP kinase phosphatases. Biochim Biophys Acta 2007, 1773:1227-1237.

62. Nishimoto S, Nishida E: MAPK signalling: ERK5 versus ERK1/2. EMBO Rep 2006, 7:782-786

63. Wilkinson MG, Millar JB: Control of the eukaryotic cell cycle by MAP kinase signaling pathways. FASEB J 2000, 14:2147-2157.

64. Sundaram MV: RTK/Ras/MAPK signaling. WormBook 2006, 1-19.

65. Yan Y, Tulasne D, Browaeys E, Cailliau K, Khayath N, Pierce RJ, Trolet J, Fafeur V, Ben YA, Dissous C: Molecular cloning and characterisation of SmSLK, a novel Ste20-like kinase in Schistosoma mansoni. Int J Parasitol 2007, 37:1539-1550.

66. Hu W, Brindley PJ, McManus DP, Feng Z, Han ZG: Schistosome transcriptomes: new insights into the parasite and schistosomiasis. Trends Mol Med 2004, 10:217-225.

67. Salzet M, Capron A, Stefano GB: Molecular crosstalk in host-parasite relationships: schistosome- and leech-host interactions. Parasitol Today 2000, 16:536-540.

68. Kemphues K: Essential genes. WormBook 2005, 1-7.

69. Jackson AL, Bartz SR, Schelter J, Kobayashi SV, Burchard J, Mao M, Li B, Cavet G, Linsley PS: Expression profiling reveals off-target gene regulation by RNAi. Nat Biotechnol 2003, 21:635-637.

70. Moffat J, Reiling JH, Sabatini DM: Off-target effects associated with long dsRNAs in Drosophila RNAi screens. Trends Pharmacol Sci 2007, 28:149-151.

71. Wilson RA, Ashton PD, Braschi S, Dillon GP, Berriman M, Ivens A: 'Oming in on schistosomes: prospects and limitations for post-genomics. Trends Parasitol 2007, 23:14-20.

72. Muhlrad PJ, Ward S: Spermiogenesis initiation in Caenorhabditis elegans involves a casein kinase 1 encoded by the spe- 6 gene. Genetics 2002, 161:143-155.

73. Reinke V, Smith HE, Nance J, Wang J, Van DC, Begley R, Jones SJ, Davis EB, Scherer S, Ward S, Kim SK: A global profile of germline gene expression in C. elegans. Mol Cell 2000, 6:605-616.

74. Bahia D, Andrade LF, Ludolf F, Mortara RA, Oliveira G: Protein tyrosine kinases in Schistosoma mansoni. Mem Inst Oswaldo Cruz 2006, 101(Suppl 1):137-143.

75. Ahier A, Khayath N, Vicogne J, Dissous C: Insulin receptors and glucose uptake in the human parasite Schistosoma mansoni. Parasite 2008, 15:573-579.

76. Khayath N, Vicogne J, Ahier A, BenYounes A, Konrad C, Trolet J, Viscogliosi E, Brehm K, Dissous C: Diversification of the insulin receptor family in the helminth parasite Schistosoma mansoni. FEBS J 2007, 274:659-676

77. Kim JJ, Accili D: Signalling through IGF-I and insulin receptors: where is the specificity? Growth Horm IGF Res 2002, 12:84-90.
78. Van BC, Sternberg PW: Epidermal growth factor signaling induces behavioral quiescence in Caenorhabditis elegans. Nat Neurosci 2007, 10:1300-1307.

79. Ramachandran H, Skelly PJ, Shoemaker CB: The Schistosoma mansoni epidermal growth factor receptor homologue, SER, has tyrosine kinase activity and is localized in adult muscle. Mol Biochem Parasitol 1996, 83:1-10.

80. Vicogne J, Cailliau K, Tulasne D, Browaeys E, Yan YT, Fafeur V, Vilain JP, Legrand D, Trolet J, Dissous C: Conservation of epidermal growth factor receptor function in the human parasitic helminth Schistosoma mansoni. J Biol Chem 2004, 279:37407-37414.

81. Ahier A, Rondard P, Gouignard N, Khayath N, Huang S, Trolet J, Donoghue DJ, Gauthier M, Pin JP, Dissous C: A new family of receptor tyrosine kinases with a venus flytrap binding domain in insects and other invertebrates activated by aminoacids. PLoS One 2009, 4:e5651.

82. Kapp K, Schussler P, Kunz W, Grevelding CG: Identification, isolation and characterization of a Fyn-like tyrosine kinase from Schistosoma mansoni. Parasitology 2001, 122:317-327.

83. Kapp K, Knobloch J, Schussler P, Sroka S, Lammers R, Kunz W, Grevelding CG: The Schistosoma mansoni Src kinase TK3 is expressed in the gonads and likely involved in cytoskeletal organization. Mol Biochem Parasitol 2004, 138:171-182.

84. Knobloch J, Winnen R, Quack M, Kunz W, Grevelding CG: A novel Sykfamily tyrosine kinase from Schistosoma mansoni which is preferentially transcribed in reproductive organs. Gene 2002, 294:87-97.

85. Bahia D, Mortara RA, Kusel JR, Andrade LF, Ludolf F, Kuser PR, Avelar L, Trolet J, Dissous C, Pierce RJ, Oliveira G: Schistosoma mansoni: expression of Fes-like tyrosine kinase SmFes in the tegument and terebratorium suggests its involvement in host penetration. Exp Parasitol 2007, 116:225-232

86. Ludolf F, Bahia D, Andrade LF, Cousin A, Capron M, Dissous C, Pierce RJ, Oliveira G: Molecular analysis of SmFes, a tyrosine kinase of Schistosoma mansoni orthologous to the members of the Fes/Fps/Fer family. Biochem Biophys Res Commun 2007, 360:163-172.

87. Manning G: Genomic overview of protein kinases. WormBook 2005, 1-19.

88. Vowels JJ, Thomas JH: Genetic analysis of chemosensory control of dauer formation in Caenorhabditis elegans. Genetics 1992, 130:105-123.

89. Parsons M, Worthey EA, Ward PN, Mottram JC: Comparative analysis of the kinomes of three pathogenic trypanosomatids: Leishmania major, Trypanosoma brucei and Trypanosoma cruzi. BMC Genomics 2005, 6:127.

90. Pils B, Schultz J: Inactive enzyme-homologues find new function in regulatory processes. J Mol Biol 2004, 340:399-404

91. Beall MJ, Pearce EJ: Human transforming growth factor-beta activates a receptor serine/threonine kinase from the intravascular parasite Schistosoma mansoni. J Biol Chem 2001, 276:31613-31619.

92. Davies SJ, Shoemaker CB, Pearce EJ: A divergent member of the transforming growth factor beta receptor family from Schistosoma mansoni is expressed on the parasite surface membrane. I Biol Chem 1998, 273:11234-11240.

93. Forrester SG, Warfel PW, Pearce EJ: Tegumental expression of a novel type II receptor serine/threonine kinase (SmRK2) in Schistosoma mansoni. Mol Biochem Parasitol 2004, 136:149-156.

94. LoVerde PT, Osman A, Hinck A: Schistosoma mansoni: TGF-beta signaling pathways. Exp Parasitol 2007, 117:304-317.

95. Osman A, Niles EG, Verjovski-Almeida S, LoVerde PT: Schistosoma mansoni TGF-beta receptor II: role in host ligand-induced regulation of a schistosome target gene. PLoS Pathog 2006, 2:e54.

96. Finn RD, Mistry J, Tate J, Coggill P, Heger A, Pollington JE, Gavin OL, Gunasekaran P, Ceric G, Forslund K, Holm L, Sonnhammer EL, Eddy SR, Bateman A: The Pfam protein families database. Nucleic Acids Res 2010, 38:D211-D222

97. Tanoue T, Yamamoto T, Nishida E: Modular structure of a docking surface on MAPK phosphatases. J Biol Chem 2002, 277:22942-22949.

98. Zhou B, Wu L, Shen K, Zhang J, Lawrence DS, Zhang ZY: Multiple regions of MAP kinase phosphatase 3 are involved in its recognition and activation by ERK2. J Biol Chem 2001, 276:6506-6515.

99. Tanoue T, Adachi M, Moriguchi T, Nishida E: A conserved docking motif in MAP kinases common to substrates, activators and regulators. Nat Cell Biol 2000, 2:110-116.

100. KEGG: Kyoto Encyclopedia of Genes and Genomes. 2000 [http://www. genome.jp/kegg/], 6-10-2009. Ref Type: Electronic Citation. 
101. Hunter S, Apweiler R, Attwood TK, Bairoch A, Bateman A, Binns D, Bork P, Das U, Daugherty L, Duquenne L, Finn RD, Gough J, Haft D, Hulo N, Kahn D, Kelly E, Laugraud A, Letunic I, Lonsdale D, Lopez R, Madera M, Maslen J, McAnulla C, McDowall J, Mistry J, Mitchell A, Mulder N, Natale D, Orengo C, Quinn AF, et al: InterPro: the integrative protein signature database. Nucleic Acids Res 2009, 37:D211-D215.

102. Bhagwat M, Aravind L: PSI-BLAST. In methods in Molecular Biology Edited by: Clifton NJ 2007, 86-177.

103. Rutherford K, Parkhill J, Crook J, Horsnell T, Rice P, Rajandream MA, Barrell B: Artemis: sequence visualization and annotation. Bioinformatics 2000, 16:944-945.

104. Notredame C: Decrease redundancy tool. 2009 [http://www.expasy.ch/ tools/redundancy], 20-11-2009. Ref Type: Electronic Citation.

105. Hall T: Bioedit: a user-friendly bioçogical sequence alignment editor and analysis program for Windows 95/98/NT. Nucl Acids Symp Ser 1999, 41:95-98.

106. Rambaut A: Tree Figure Drawing Tool, Version 1.3.1. 2010 [http://tree.bio. ed.ac.uk/software/figtree], 1-3-2010. Ref Type: Electronic Citation.

107. Anamika K, Srinivasan N: Comparative kinomics of Plasmodium organisms: unity in diversity. Protein Pept Lett 2007, 14:509-517.

108. Ghedin E, Wang S, Spiro D, Caler E, Zhao Q, Crabtree J, Allen JE, Delcher AL, Guiliano DB, Miranda-Saavedra D, Angiuoli SV, Creasy T, Amedeo P, Haas B, El-Sayed NM, Wortman JR, Feldblyum T, Tallon L, Schatz M, Shumway M, Koo H, Salzberg SL, Schobel S, Pertea M, Pop M, White O, Barton GJ, Carlow CK, Crawford MJ, Daub J, et al: Draft genome of the filarial nematode parasite Brugia malayi. Science 2007, 317:1756-1760.

109. Caenepeel S, Charydczak G, Sudarsanam S, Hunter T, Manning G: The mouse kinome: discovery and comparative genomics of all mouse protein kinases. Proc Natl Acad Sci USA 2004, 101:11707-11712.

110. Zdobnov EM, von MC, Letunic I, Torrents D, Suyama M, Copley RR, Christophides GK, Thomasova D, Holt RA, Subramanian GM, Mueller HM, Dimopoulos G, Law JH, Wells MA, Birney E, Charlab R, Halpern AL, Kokoza E, Kraft CL, Lai Z, Lewis S, Louis C, Barillas-Mury C, Nusskern D, Rubin GM, Salzberg SL, Sutton GG, Topalis P, Wides R, Wincker P, et al: Comparative genome and proteome analysis of Anopheles gambiae and Drosophila melanogaster. Science 2002, 298:149-159.

111. Ren J, Wen L, Gao X, Jin C, Xue Y, Yao X: DOG 1.0: illustrator of protein domain structures. Cell Res 2009, 19:271-273.

doi:10.1186/1471-2164-12-215

Cite this article as: Andrade et al:: Eukaryotic Protein Kinases (ePKs) of the Helminth Parasite Schistosoma mansoni. BMC Genomics 2011 12:215.

\section{Submit your next manuscript to BioMed Central and take full advantage of:}

- Convenient online submission

- Thorough peer review

- No space constraints or color figure charges

- Immediate publication on acceptance

- Inclusion in PubMed, CAS, Scopus and Google Scholar

- Research which is freely available for redistribution 